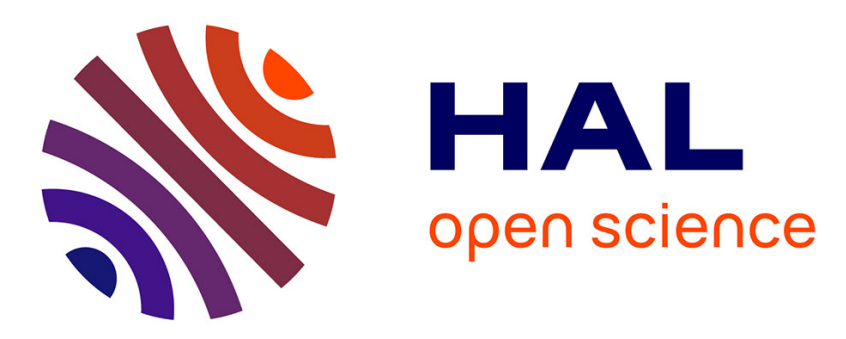

\title{
Transport and carbon exchanges in Red Sea inverse methodology
}

Nicolas Metzl, Berrien Moore Iii, Anne Papaud, Alain Poisson

\section{To cite this version:}

Nicolas Metzl, Berrien Moore Iii, Anne Papaud, Alain Poisson. Transport and carbon exchanges in Red Sea inverse methodology. Global Biogeochemical Cycles, 1989, 3, pp.1-26. 10.1029/GB003i001p00001 . hal-02991979

\section{HAL Id: hal-02991979 \\ https://hal.science/hal-02991979}

Submitted on 18 Mar 2021

HAL is a multi-disciplinary open access archive for the deposit and dissemination of scientific research documents, whether they are published or not. The documents may come from teaching and research institutions in France or abroad, or from public or private research centers.
L'archive ouverte pluridisciplinaire HAL, est destinée au dépôt et à la diffusion de documents scientifiques de niveau recherche, publiés ou non, émanant des établissements d'enseignement et de recherche français ou étrangers, des laboratoires publics ou privés. 
GLOBAL BIOGEOCHEMICAL CYCLES, VOL. 3, NO. 1, PAGES 1-26, MARCH 1989

\section{TRANSPORT AND CARBON EXCHANGES IN RED SEA INVERSE METHODOLOGY}

\author{
Nicolas Metzl \\ Laboratoire de Physique et Chimie Marines, \\ Université Pierre et Marie Curie, Paris
}

Berrien Moore III

Institute for the Study of Earth, Oceans, and Space, University of New Hampshire, Durham

Anne Papaud and Alain Poisson

Laboratoire de Physique et Chimie Marines, Université Pierre et Marie Curie, Paris

\begin{abstract}
In this paper, we use an inverse methodology to parameterize a box model of the Red Sea to study carbon exchanges and transport. In this application, we use simultaneously the information contained in physical and biogeochemical tracer profiles such as temperature, salinity, dissolved inorganic carbon, alkalinity, oxygen, and phosphate. Since the Red Sea is subject to a seasonal monsoon regime and because we are interested in resolving exchanges from the surface to the bottom, we have decoupled the temporal regime into two seasons : winter (November to May) and summer (June to October). We present the two solutions which include advective and mixing (eddy diffusion) exchanges as well as new primary production, decomposition, carbonate formation, and dissolution. The circulation is reversed from one season to the next. The net biological exchanges (new production) of carbon, compatible with the dynamical solutions, are almost null for the organic processes (negative in summer, positive in winter); the budgets for the mineral processes are negative for both seasons. This result is consistent with the view that carbonates play an important role in the budget of carbon in Red Sea. Finally, taking advantage of richer data sets for the summer season, we present two box designs for this period. It appears that transport solutions are sensitive to the choice of box topology, whereas biochemical exchanges are roughly the same for both designs.

\section{INTRODUCTION}

Understanding and quantifying the different components that govern the uptake and more generally the distribution of partial

Copyright 1989

by the American Geophysical Union.

Paper number 88GB04128. 0886-6236/89/88GB-04128\$10.00 pressure of $\mathrm{CO}_{2}$ in the oceans is one of the major problems in marine biogeochemistry. A coherent representation for the carbon fluxes requires knowledge of not only oceanic circulation but also biological processes within oceanic regions and the boundary fluxes. The problem, therefore, is one of specifying the quantitative role of each process which affects this distribution. One approach is to use, via an inverse methodology, biogeochemical and physical tracers from which one can extract specification and quantification of processes. The philosophy of the inverse method in which tracers, such as oxygen, nutrients and dissolved carbon, are used to infer the rates of both physical and biological processes, is at the center of chemical oceanography as well as at its interfaces with physical and biological oceanography (for example, "biochemical processes are responsible for the existence of oxygen minima, but the circulation is responsible for the position" [Wyrtki , 1962]).

A series of recent works [Wunsch and Minster, 1982; Bolin et al., 1983; Wunsch, 1984; Mercier, 1986; Schlitzer, 1987; Bolin et al., 1987; Garçon and Minster, 1988] shows that box models using generalized inverses are attractive tools for combining the physical or biogeochemical information. These studies also provide insight into the difficulties inherent in such investigations. Specifically, they show, for example, that poor resolution can be responsible for poor or uncertain parameter estimation [Bolin et al., 1983] or that incompatibilities can exist between external forcing and box design [Garçon and Minster, 1988]. This latter problem is compounded by the fact that since oceanographic data are not well distributed in time and since external forcings are variable with seasons, this must raise questions about their use in the formulation of steady state models.

In light of these difficulties, it appears interesting to study a multibox model in a well-defined marine region, the Red Sea, where the circulation is seasonally reversed (monsoon regime) and to examine the capacity of such a model to describe the dynamical and biochemical processes on both spatial and 
temporal (seasonal) scales. For the Red Sea, data on temperature, salinity, dissolved inorganic carbon, alkalinity, oxygen and phosphate were collected during Merou A and B expeditions in June and October 1982 [Beauverger et al., 1984a,b] and during a GEOSECS expedition in December 1977 [Weiss et al., 1983]. Using these data, we have constructed a 19-box model of the Red Sea, for summer and winter regimes. The topology (box design) is two-dimensional (latitude-depth). This simplification is in agreement with the geographic scale of the basin, the data sections, and the absence of geostrophy constraints. Thus, in our formulation, there is no theoretical assumption other than the conservation of tracers. In order to develop a sensitivity experiment on the model's topology, a 44-box model for the summer conditions only is also employed. We first describe briefly the model's parameters (and how they are included within linearized tracer equations) and each term (for example, external forcing, constraints on unknowns) that is needed to perform the inversion. Finally, we present the solutions for each season and for the two designs for the summer version.

\section{THE MODEL STRUCTURE}

\subsection{Equations and System}

The processes that we investigate are the same as in the 12-box model of Bolin et al. [1983] for the global ocean. The unknowns (components of solution vector) correspond to the advective circulation; the mixing (eddy diffusion), which characterizes the fluctuations on spatial scales smaller than the discretization scale; and the internal production or consumption of dissolved inorganic carbon by exchanges of organic or mineral (carbonates) carbon by the marine biosphere. On the other hand, external exchanges or boundary fluxes at the ocean-atmosphere, ocean-sediment, and ocean-ocean interfaces, will be considered to be known and will constitute the forcing parameters. All these parameters (unknowns and forcing terms) are included in the differential transport equation (1), which describes the variation of a scalar quantity $q\left(x_{1}, x_{2}, t\right)$ contained in a fluid particle and driven by the dynamics (advection-diffusion):

$\partial q / \partial t+\nabla \cdot(q V)-\nabla \cdot(K \nabla \cdot q)=f_{q}$

Here, $\nabla$ is the vector $\left(\partial / \partial \mathrm{x}_{1}, \partial / \partial \mathrm{x}_{2}\right)$, and the center dot denotes inner product; $q\left(x_{1}, x_{2}, t\right)$ is a material or heat quantity by volume unit (for example, q may be density (kilograms per cubic meter) times alkalinity (milliequivalents per kilogram) and have units of milliequivalents per cubic meter) at position $x_{1}, x_{2}$ at time $t, V$ is the advective vector, $K$ is the tensor of turbulent diffusion, and $\mathrm{f}_{\mathrm{q}}$ contains the internal and external sources and sinks corresponding to property $\mathrm{q}$. We should mention that in this application we do not use ${ }^{14} \mathrm{C}$ (since the time and spatial scales are inappropriate); consequently, there is no decay of radioactive substance in (1).

If we assume stationarity $(\partial q / \partial t=0),(1)$ defines the conservation of the quantity $q\left(x_{1}, x_{2}\right)$, and becomes $\nabla \cdot(\mathrm{qV})-\nabla \cdot(\mathrm{K} \nabla \cdot \mathrm{q})=\mathrm{f}_{\mathrm{q}}$

For a particular volume $w_{i}$ of "box" $i$, of the domain, we can write the integrated form of (2) as

$\iint_{s i}\left(V_{n} q-K_{n} \partial q / \partial x_{n}\right) d s=\iiint_{w i} f_{q} d w$

The subscript $n(n=1,2)$ denotes the normal to the entire surface si of box $\mathrm{i}$; wi is the volume of the box $\mathrm{i}$; and ds and $\mathrm{dw}$ are the elemental surface and volume.

In this study, we are interested in quantifying processes which participate in the budget of dissolved inorganic carbon; for box $i$ the source (or sink) term $\mathrm{f}_{\mathrm{q}, \mathrm{i}}$ (with $\mathrm{f}_{\mathrm{q}, \mathrm{i}}=\mathrm{f}_{\mathrm{q}}$ wi ) can be decomposed into internal $\left(\mathrm{fl}_{\mathrm{q}, \mathrm{i}}\right)$ and external $\left(\mathrm{fe}_{\mathrm{q}, \mathrm{i}}\right)$ exchanges according to

$f_{q, i}=f_{q, i}+f e_{q, i}=g_{q, o} c o_{i}+g_{q, m} c m_{i}+f e_{q, i}$

where, $\mathrm{CO}_{\mathrm{i}}$ and $\mathrm{cm}_{\mathrm{i}}$ are the net production or consumption of dissolved inorganic carbon by exchange with organic matter $\left(\mathrm{Co}_{\mathfrak{j}}\right)$ and carbonates $\left(\mathrm{cm}_{\mathfrak{i}}\right)$ within the box $\mathrm{i}$. Parametrization of these biochemical processes is linear; $\mathrm{g}_{\mathrm{q}, \mathrm{o}}$ and $\mathrm{g}_{\mathrm{q}, \mathrm{m}}$ are the Redfield ratios [Redfield et al., 1963] linking the tracer $q$ and the carbon involved in the organic and mineral $\left(\mathrm{CaCO}_{3}\right)$ system.

We use the Redfield ratios $(\mathrm{C} / \mathrm{O} / \mathrm{P}=106 /-136 / 0.9)$ computed for the Red Sea by Papaud and Poisson [1986], and we assume that $\mathrm{g}_{\mathrm{q}, \mathrm{o}}$ or $\mathrm{g}_{\mathrm{q}, \mathrm{m}}$ are the same for all boxes.

For the box $\mathrm{j}$ in contact with the box $\mathrm{i}$, we estimate the left-hand side of ( $3 a$ ) by using a finite difference approximation defining $\left(q_{i}+q_{j}\right) / 2$ for the mean quantity at the $s_{i j}$ interface of boxes $i$ and $j$, and $\left(q_{i}-q_{j}\right) / D_{i j}$ for the gradient with reference to distance $D_{i j}$ between the centers of boxes $i$ and $j$. Summing on boxes $j$ in contact with the box $i,(3 a)$ and $(3 b)$ lead to the following linearized equation that expresses the budget of property $q$ for box $\mathrm{i}$ between internal processes (left-hand side) and extermal exchanges (right-hand side); $v_{\mathrm{ij}}$ and $\mathrm{k}_{\mathrm{ij}}$ represent $V_{n}$ and $K_{n}(\sec (3 a))$ over interface $s_{i j}$.

$$
\begin{aligned}
{\left[\Sigma_{j} v_{i j} s_{i j}\left(q_{i}+q_{j}\right) / 2\right.} & \left.-k_{i j} s_{i j}\left(q_{i}-q_{j}\right) / D_{i j}\right] \\
& -g_{q, o} c o_{i}-g_{q, m} c m_{i}=f_{q}, i
\end{aligned}
$$

The parameters of (4) are represented on Figure 1. This linearized budget formulation can be written for each box and for each tracer. If we have $\mathrm{N}$ tracers (plus the continuity equation which is the tracer equation where mass is the tracer), I boxes and $L$ interfaces, the equations (4) form a system of $(\mathrm{N}+1) \mathrm{I}$ equations with $2(\mathrm{~L}+\mathrm{I})$ unknowns. It will be written in matricial form :

$\mathbf{A X}=\mathbf{B}$

where $A$ is the $\{(N+1) I, 2(L+I)\}$ matrix constructed from the box data $q_{i}$ and $q_{j}, X$ is the $2(L+I)$ vector of unknowns $\left(v_{i j} s_{i j}\right.$, $\left.\mathbf{k}_{\mathrm{ij}} \mathrm{s}_{\mathrm{ij}} / \mathrm{D}_{\mathrm{ij}}, \mathrm{co}_{\mathrm{i}}, \mathrm{cm}_{\mathrm{i}}\right)$, and $\mathrm{B}$ is the $(\mathrm{N}+1) \mathrm{I}$ vector of external constraints. The generalized inversion of the A matrix (pseudoinverse) or equivalently, the minimization of the 


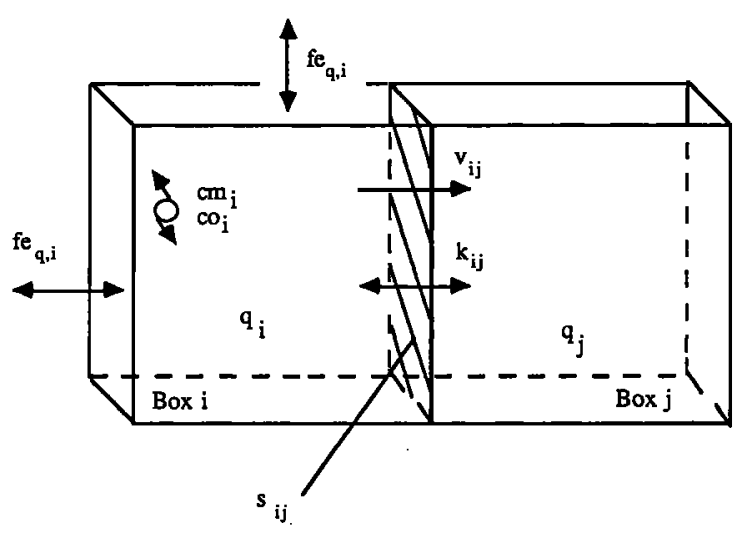

Fig. 1. Box representation of parameters in (4).

Euclidian norm \|AX-B\|, is not sufficient to insure a physically meaningful solution. For instance, there is nothing in the mathematical formulation to insure that new production takes place in the euphotic zone and not below [Bolin et al., 1983]. Consequently, we impose on the solution a set of $H$ convex constraints (which will be described in section 2.4) according to

GX $\geq \mathbf{H}$

where $\mathbf{G}$ is a $\{H, 2(L+I)\}$ matrix, $X$ is the $2(L+1)$ unkrown vector, and $H$ is a $H$ vector. The overall system (5) and (6) is resolved by a "least squares with linear inequality constraints" method (LSI programming in Lawson and Hanson, [1974]).

\subsection{Seasonal Uncoupling, Discretization, and Data.}

The Red Sea is subject to the monsoon winds regime (Figure 2), which follows a well-established pattern [Patzert, 1972, 1974]: from June to September, the wind blows from NNW throughout the entire basin, which induces in the surface an outflow of Red Sea water toward the Gulf of Aden, producing an upwelling in the north and the formation of subsurface inflow of Aden waters. From October to May, the wind is SSE in the southern part of basin, which results in an inflow of the Indian Ocean waters toward the NW, a slope in the northem portion of the Red Sea and a warm, saline subsurface current toward SE that reaches the Gulf of Aden. Because of this wind-driven reversal as well as seasonal biochemical activity, tracer data within the basin reflect seasonal variability [Morcos, 1970; Poisson et al., 1984] especially in surface and subsurface waters. Similarly, budgets of salinity or nutrients at the strait of Bab-el-Mandab are, themselves, seasonal (Poisson et al., 1984; E. Souvermezoglou et al., Red Sea budgets of salinity, nutrients and carbon calculated in the strait of Bab-el-Mandab during the summer and winter seasons, submitted to Joumal of Marine Research, 1988 (hereinafter Souvermezoglou et al. (1988))]. Therefore, we must take into account this temporal dependence in the model in order to obtain a realistic transport scheme as well as the rate and pattern of carbon exchanges with biological processes. For that, we decouple the model into two seasons and apply it independently for summer (June to October) and winter (November to May) conditions.
If the wind forces the dynamical seasonal inversion (as it does in the Red Sea), then the isopycnal distributions are not very variable from one season to the other (Figure 3 ). Near the surface, the isopycnals rise in the north of basins during the year (the evaporation gradient is positive toward the higher latitude in both seasons); in deep levels, the density gradient is weak. This configuration permits one to keep the same topology for summer and winter applications (Figure 4). Horizontal limits are logically constructed to separate surface, intermediate and deep water. In the north, the interfaces approach the surface as do the isopycnals (see Figure 3). In the same way, bottom layer decreases with depth from north $(800 \mathrm{~m})$ to south $(1200 \mathrm{~m})$ following 28.61 potential density. A vertical boundary at $21^{\circ} \mathrm{N}$ is defined to separate northem and southern parts of the basin. Since there is deep water formation in the extreme northem portion [Morcos, 1970; Manins, 1973; Maillard, 1974; Morcos and Soliman, 1974; Kuntz, 1985], we also define a boundary at $27^{\circ} \mathrm{N}$. In the southern part, boxes are defined in order to separate information on the internal return flow of deep water within the basin and the upwelling of deep water which reaches Bab-el-Mandab strait below $200 \mathrm{~m}$ and exits toward the Gulf of Aden [Manins, 1973]. Thus, the box design is neither purely isopycnal nor depth determined; it is oriented both to insure independent information on water properties used as input data in the model (matrix A) and to capture "a priori" knowledge on circulation in Red Sea (seasonal reversed circulation, downwelling in north, upwelling of deep water in south).

In order to compare summer and winter applications with regard to the information used in the model, we have selected

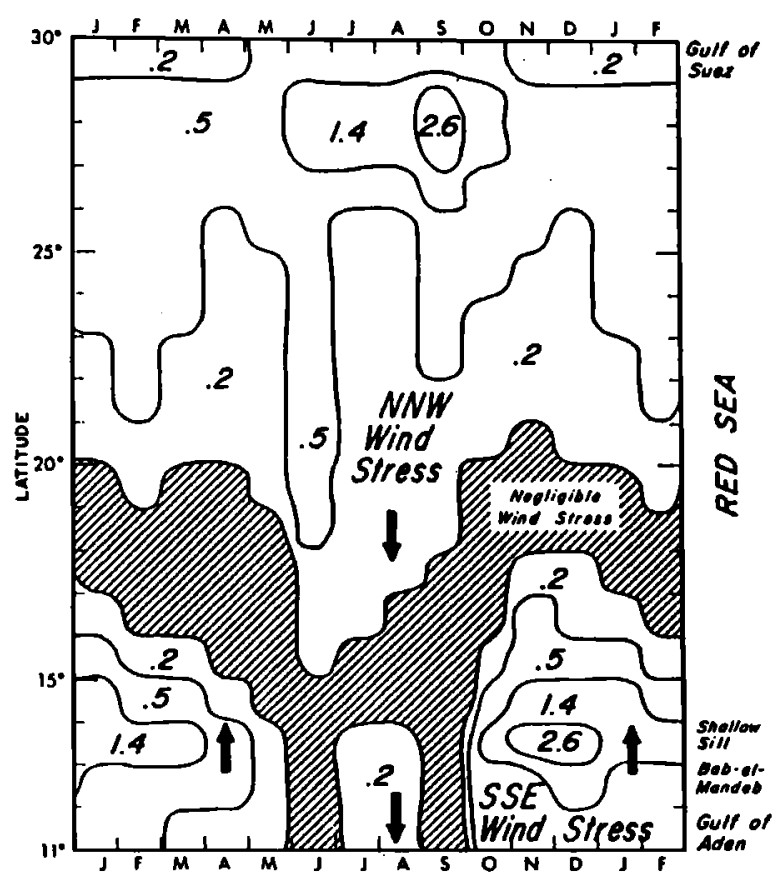

Fig. 2. Magnitude and direction of monthly mean wind stress at the sea surface (dynes per square centimeter). January and February are repeated [from Patzert, 1972]. 


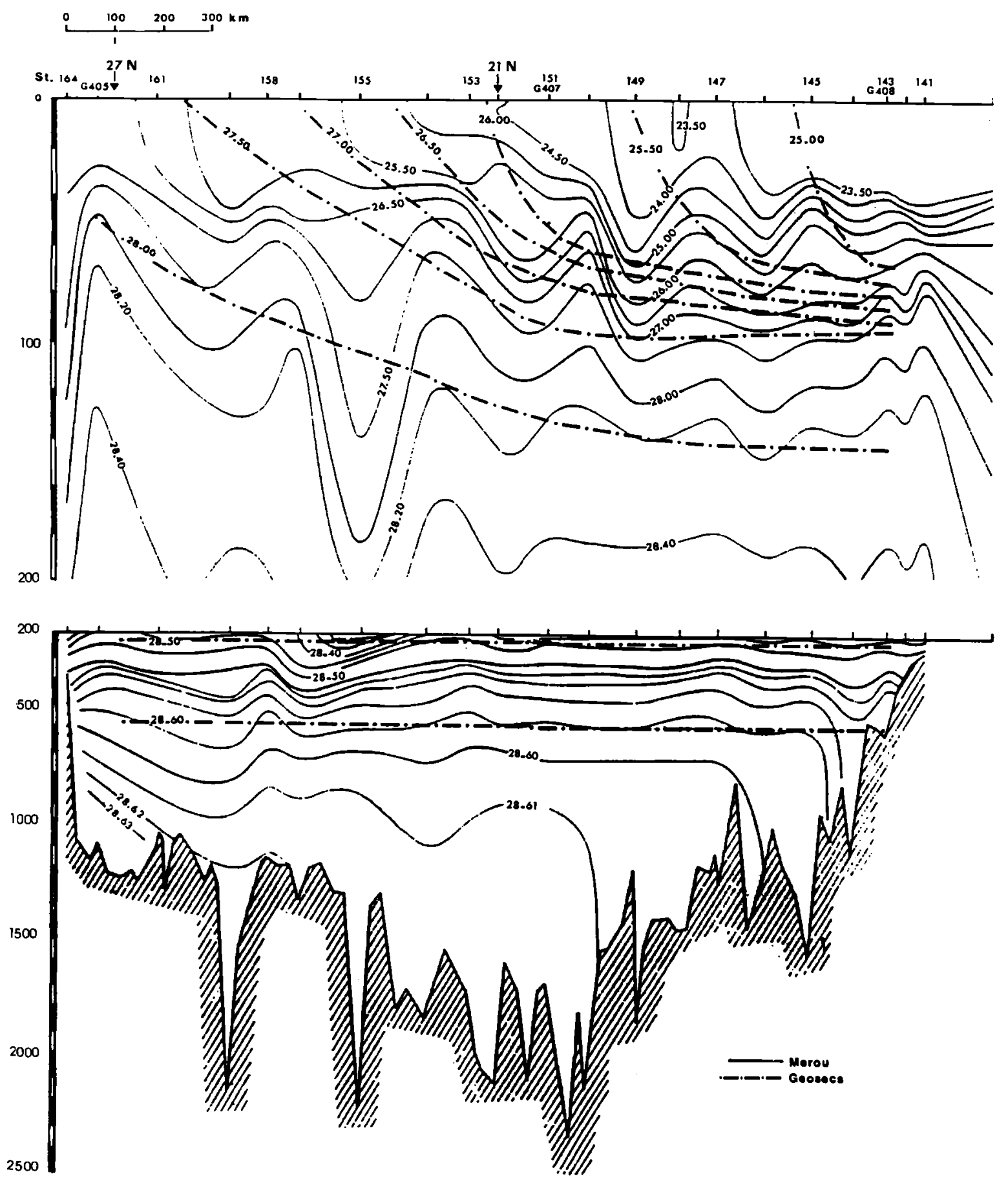

Fig. 3. Isopycnal section (sigma-theta) of Red Sea (adapted from Maillard and Soliman [1985]). The summer data (Merou-B) and winter data (GEOSECS) are superposed.

the same tracers for the two seasons : heat (hereinafter denoted $T)$, salinity $(S)$, total dissolved inorganic carbon $(\Sigma C)$, total alkalinity $(\mathrm{TA})$, oxygen $\left(\mathrm{O}_{2}\right)$, phosphate $\left(\mathrm{PO}_{4}\right)$. In addition to these six tracers, we include the mass $(\mathrm{M})$ budget for each box. Positions of samples used are shown in Figure 4; the box data computed are presented in Table 1 and in Figures 5a and $5 \mathrm{~b}$. For the summer season, we used the data of 10 Merou-B stations (September 1982) described by Beauverger et al. 


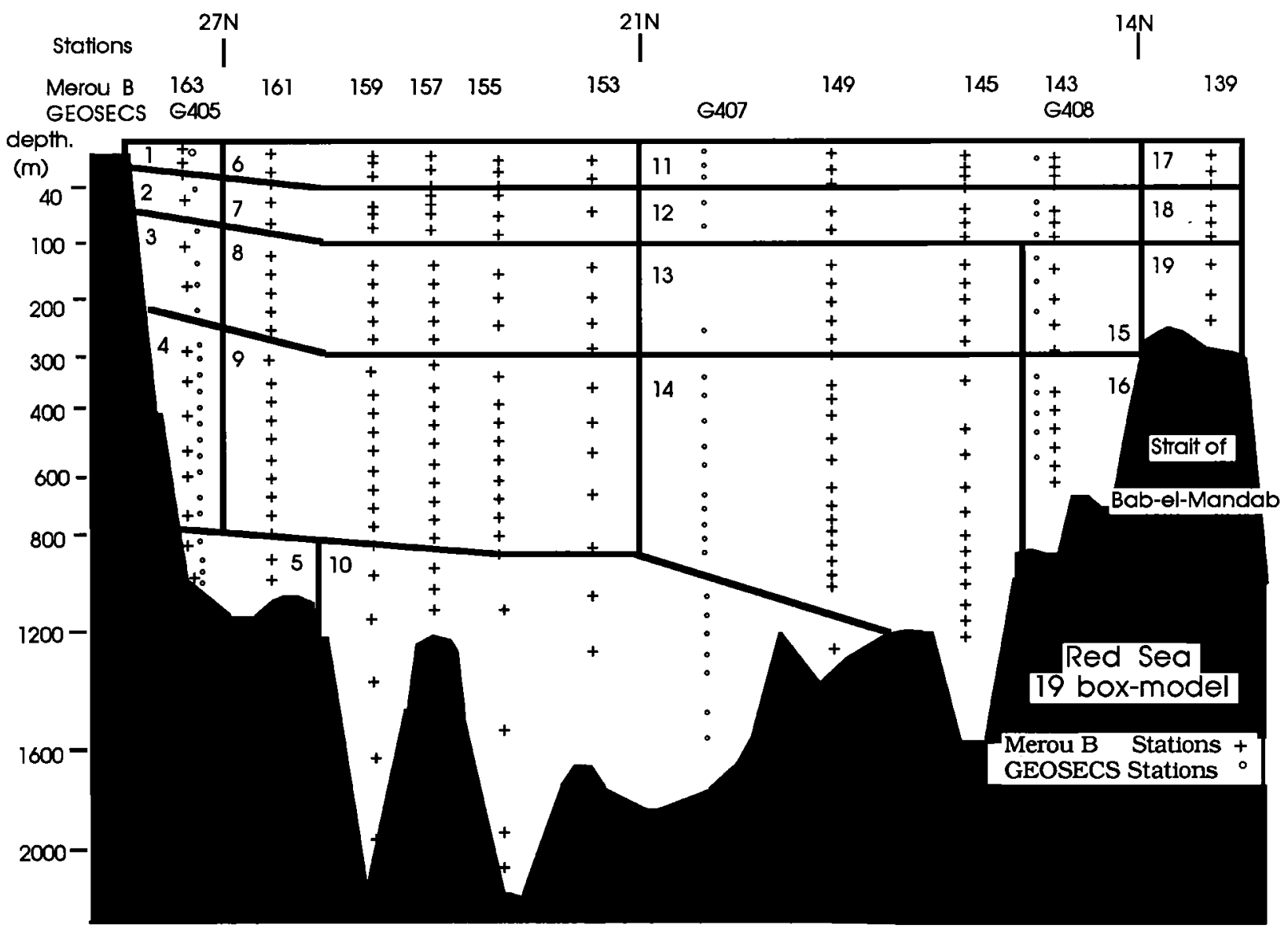

Fig. 4. Two-dimensional box design for the 19-box model (box number used in text and in Table 1 are specified in each box). Stations and data positions of Merou-B (pluses) and GEOSECS (circles) used in the computations of box data.

[1984a,b]; for winter, we have the same type of information [Weiss et al., 1983] for three GEOSECS stations (December 1977). We do not use the data of the Merou-A cruise (June 1982). During June, the surface current in the Bab-el-Mandab strait is still toward NNW, the opposite of the wind regime [Neumann and McGill, 1962; Maillard and Soliman, 1985]; hence this intermediate period (the June data) is not representative of a well-established regime, for either the circulation [Maillard and Soliman, 1985] or for the exchanges of properties like oxygen, phosphate, and dissolved inorganic carbon [Poisson et al., 1984]. Finally, we note that the topology consists of 19 boxes and 31 internal interfaces (Figure 4). Consequently, there are 31 advection terms $\left(v_{i j}\right), 31$ mixing coefficients $\left(\mathrm{k}_{\mathrm{ij}}\right)$ and 38 biochemical exchanges $\left(\mathrm{co}_{\mathrm{i}}\right.$ and $\left.\mathrm{cm}\right)$; thus, in system (5), the dimension of the $X$ vector of unknowns is 100. By using budgets of seven $(\mathrm{N}+1)$ different properties we set $19 \times 7=133$ equations. Therefore, system (5) is formally overdetermined or incompatible with the dimension $(133,100)$.

\subsection{Boundary Constraints}

In the previous paragraph we have described $\mathbf{A X}$, the left-hand side of the system (5); matrix $\mathbf{A}(133,100)$ contains terms $q_{i}+q_{j} / 2, q_{i}-q_{j}, g_{o, q}$ and $g_{m, q} ; X$ is the 100 -vector of unknowns. In order to solve the system (5), one requires knowledge of external forcing (the vector $B$ or right-hand side) at the boundaries. The inversion then uses the tracer distributions, which are reflected in $A$, and the forcing at the boundaries, which is given by vector $B$, to resolve the processes within the basin (the $\mathbf{X}$ vector). Thus, for each season, each tracer and each box in contact with limit of the domain, we must determine the term $f_{\mathrm{q}_{\mathrm{i}} \mathrm{i}}$ in (4) that is consistent with an annual stationarity assumption. In the following subsections, we describe each type of external exchange for each of the tracers that we have computed in constructing the vector $\mathbf{B}$.

There are three main types of external process : ocean-atmosphere interface exchanges (for $\mathrm{M}, \mathrm{T}, \mathrm{\Sigma C}$ and $\mathrm{O}_{2}$ ), 
TABLE 1. Box Data for 19-Box and

\begin{tabular}{|c|c|c|c|c|c|c|c|c|c|}
\hline \multicolumn{2}{|c|}{ Box Number } & \multicolumn{2}{|c|}{$\begin{array}{l}\text { Volume, } \\
10^{3} \mathrm{~km}^{3}\end{array}$} & \multicolumn{3}{|c|}{$\mathrm{T},{ }^{\circ} \mathrm{C}$} & \multicolumn{3}{|c|}{$\mathrm{s}$} \\
\hline $\begin{array}{l}\text { Model } \\
\quad 19\end{array}$ & $\begin{array}{l}\text { Mode1 } \\
44\end{array}$ & $\begin{array}{c}\text { Model } \\
19\end{array}$ & $\begin{array}{l}\text { Model } \\
44\end{array}$ & $\begin{array}{c}\text { Model } \\
\text { 19s }\end{array}$ & $\begin{array}{l}\text { Model } \\
44 \mathrm{~s}\end{array}$ & $\begin{array}{l}\text { Model } \\
19 \mathrm{w}\end{array}$ & $\begin{array}{l}\text { Model } \\
19 \mathrm{~s}\end{array}$ & $\begin{array}{l}\text { Model } \\
44 \mathrm{~s}\end{array}$ & $\begin{array}{c}\text { Model } \\
19 \mathrm{w}\end{array}$ \\
\hline 1 & 1 & 0,7 & 0,7 & 25,800 & 25,800 & 23,230 & 40,351 & 40,351 & 40,396 \\
\hline 2 & 2 & 1,1 & 1,1 & 22,750 & 22,750 & 22,680 & 40,384 & 40,384 & 40,380 \\
\hline \multirow[t]{2}{*}{3} & 3 & 3,3 & 3,3 & 21,730 & 21,730 & 21,740 & 40,478 & $\begin{array}{l}40,478 \\
40,576\end{array}$ & 40,454 \\
\hline & $\begin{array}{l}4 \\
5\end{array}$ & & 3,9 & & 21,620 & & & 40,576 & \\
\hline 4 & $\begin{array}{l}5 \\
6\end{array}$ & 5,1 & $\begin{array}{l}1,2 \\
0,8\end{array}$ & 21,570 & $\begin{array}{l}21,530 \\
21,490\end{array}$ & 21,530 & 40,586 & $\begin{array}{l}40,594 \\
40,592\end{array}$ & 40,569 \\
\hline 5 & $\begin{array}{r}12 \\
7 \\
13\end{array}$ & 2,8 & $\begin{array}{r}2 \\
1,8 \\
2,2\end{array}$ & 21,490 & $\begin{array}{l}21,490 \\
27,430 \\
28,470\end{array}$ & 21,440 & 40,591 & $\begin{array}{l}40,590 \\
40,100 \\
39,788\end{array}$ & 40,586 \\
\hline 6 & $\begin{array}{r}19 \\
8 \\
14\end{array}$ & 5,8 & $\begin{array}{l}1,8 \\
2,7 \\
3,3\end{array}$ & 28,175 & $\begin{array}{l}28,555 \\
24,070 \\
24,170\end{array}$ & 24,980 & 39,823 & $\begin{array}{l}39,590 \\
40,277 \\
39,989\end{array}$ & 39,950 \\
\hline \multirow[t]{2}{*}{7} & $\begin{array}{r}20 \\
9\end{array}$ & 8,7 & $\begin{array}{l}2,7 \\
8,2\end{array}$ & 24,235 & $\begin{array}{l}24,475 \\
21,910\end{array}$ & 24,100 & 40,031 & $\begin{array}{l}39,840 \\
40,448\end{array}$ & 40,066 \\
\hline & 15 & & 10,2 & & 22,100 & & & 40,349 & \\
\hline \multirow[t]{5}{*}{8} & 21 & 26,9 & 8,5 & 22,100 & 22,280 & 21,920 & 40,371 & 40,323 & 40,434 \\
\hline & $\begin{array}{l}10 \\
16\end{array}$ & & $\begin{array}{r}9,4 \\
15,2\end{array}$ & & $\begin{array}{l}21,640 \\
21,645\end{array}$ & & & $\begin{array}{l}40,569 \\
40,541\end{array}$ & \\
\hline & 22 & & 11 & & 21,635 & & & 40,560 & \\
\hline & 11 & & 2,9 & & 21,565 & & & 40,595 & \\
\hline & 17 & & 7,3 & & 21,570 & & & 40,579 & \\
\hline \multirow[t]{3}{*}{9} & 23 & 54,5 & 8,7 & 21,600 & 21,570 & 21,580 & 40,573 & 40,583 & 40,582 \\
\hline & 18 & & 5,3 & & 21,510 & & & 40,585 & \\
\hline & 24 & & 6 & & 21,530 & & & 40,584 & \\
\hline \multirow[t]{3}{*}{10} & 30 & 20,3 & 9 & 21,550 & 21,570 & 21,520 & 40,586 & 40,588 & 40,601 \\
\hline & 25 & & 5,6 & & 30,260 & & & 38,726 & \\
\hline & 31 & & 3 & & 30,430 & & & 37,797 & \\
\hline \multirow[t]{3}{*}{11} & 36 & 9,8 & 1,2 & 30,460 & 31,090 & 26,950 & 38,269 & 37,647 & 38,587 \\
\hline & 26 & & 8,2 & & 26,260 & & & 39,031 & \\
\hline & 32 & & 4,1 & & 21,830 & & & 37,439 & \\
\hline \multirow[t]{2}{*}{12} & 37 & 13,7 & 1,4 & 24,220 & 21,880 & 25,470 & 38,280 & 37,361 & 39,075 \\
\hline & 27 & & 23 & & 22,110 & & & 40,404 & \\
\hline \multirow[t]{3}{*}{13} & 33 & 33,9 & 10,9 & 22,100 & 22,080 & 22,120 & 40,399 & 40,389 & 40,405 \\
\hline & $\begin{array}{l}28 \\
34\end{array}$ & & $\begin{array}{r}22,8 \\
7,1\end{array}$ & & $\begin{array}{l}21,640 \\
21,640\end{array}$ & & & $\begin{array}{l}40,569 \\
40,563\end{array}$ & \\
\hline & 29 & & 19,7 & & 21,580 & & & 40,581 & \\
\hline 14 & 35 & 55,4 & 5,8 & 21,610 & 21,610 & 21,620 & 40,577 & 40,590 & 40,594 \\
\hline \multirow{2}{*}{15} & 38 & 3,1 & 3,1 & 21,850 & 21,850 & 22,100 & 40,251 & 40,251 & 40,395 \\
\hline & 39 & & 1,7 & & 21,670 & & & 40,574 & \\
\hline 16 & 40 & 2,7 & 1 & 21,650 & 21,630 & 21,650 & 40,580 & 40,584 & 40,590 \\
\hline & 41 & 0,45 & 0,45 & 29,780 & 21,780 & 26,310 & 36,761 & 36,761 & 36,734 \\
\hline \multirow{2}{*}{18} & 42 & 0,4 & 0,4 & 20,740 & 20,740 & 23,310 & 36,245 & 36,245 & 36,877 \\
\hline & 43 & & 0,32 & & 19,610 & & & 38,134 & \\
\hline 19 & 44 & 0,35 & 0,03 & 20,180 & 20,230 & 19,350 & 38,600 & 38,616 & 37,985 \\
\hline
\end{tabular}

The letters "s" and " $w$ " denote summer and winter, respectively. The box boxes of the 19-box model (i.e., boxes 18, 24, and 30 are equivalent to 
44-Box Models for Each Tracer

\begin{tabular}{|c|c|c|c|c|c|c|c|c|c|c|c|}
\hline \multicolumn{3}{|c|}{$\Sigma \mathrm{C}, \mathrm{mmol} / \mathrm{kg}$} & \multicolumn{3}{|c|}{ TA, meq/kg } & \multicolumn{3}{|c|}{$\mathrm{O}_{2}, \mathrm{mmol} / \mathrm{kg}$} & \multicolumn{3}{|c|}{$\mathrm{PO}_{4}$, umol/kg } \\
\hline $\begin{array}{c}\text { Model } \\
19 s\end{array}$ & $\begin{array}{c}\text { Model } \\
44 \mathrm{~s}\end{array}$ & $\begin{array}{c}\text { Model } \\
19 w\end{array}$ & $\begin{array}{c}\text { Model } \\
19 s\end{array}$ & $\begin{array}{c}\text { Model } \\
44 \mathrm{~s}\end{array}$ & $\begin{array}{c}\text { Model } \\
19 \mathrm{w}\end{array}$ & $\begin{array}{c}\text { Model } \\
19 s\end{array}$ & $\begin{array}{c}\text { Model } \\
44 \mathrm{~s}\end{array}$ & $\begin{array}{c}\text { Model } \\
19 w\end{array}$ & $\begin{array}{c}\text { Model } \\
19 s\end{array}$ & $\begin{array}{l}\text { Model } \\
44 \mathrm{~s}\end{array}$ & $\begin{array}{c}\text { Model } \\
19 w\end{array}$ \\
\hline $\begin{array}{l}2,061 \\
2,082 \\
2,119\end{array}$ & $\begin{array}{l}2,061 \\
2,082 \\
2,119 \\
2,162\end{array}$ & $\begin{array}{l}2,102 \\
2,114 \\
2,156\end{array}$ & $\begin{array}{l}2,470 \\
2,468 \\
2,460\end{array}$ & $\begin{array}{l}2,470 \\
2,468 \\
2,460 \\
2,441\end{array}$ & $\begin{array}{l}2,480 \\
2,473 \\
2,463\end{array}$ & $\begin{array}{l}0,203 \\
0,195 \\
0,141\end{array}$ & $\begin{array}{l}0,203 \\
0,195 \\
0,141 \\
0,079\end{array}$ & $\begin{array}{l}0,210 \\
0,196 \\
0,142\end{array}$ & $\begin{array}{l}0,11 \\
0,14 \\
0,49\end{array}$ & $\begin{array}{l}0,11 \\
0,14 \\
0,49 \\
0,84\end{array}$ & $\begin{array}{l}0,06 \\
0,13 \\
0,48\end{array}$ \\
\hline 2,152 & $\begin{array}{l}2,145 \\
2,136\end{array}$ & 2,188 & 2,448 & $\begin{array}{l}2,453 \\
2,458\end{array}$ & 2,450 & 0,097 & $\begin{array}{l}0,111 \\
0,129\end{array}$ & 0,077 & 0,70 & $\begin{array}{l}0,59 \\
0,48\end{array}$ & 0,82 \\
\hline 2,140 & $\begin{array}{l}2,142 \\
2,047 \\
2,038\end{array}$ & 2,166 & 2,456 & $\begin{array}{l}2,455 \\
2,460 \\
2,448\end{array}$ & 2,456 & 0,123 & $\begin{array}{l}0,120 \\
0,199 \\
0,197\end{array}$ & 0,119 & 0,52 & $\begin{array}{l}0,54 \\
0,10 \\
0,08\end{array}$ & 0,58 \\
\hline 2,037 & $\begin{array}{l}2,025 \\
2,064 \\
2,059\end{array}$ & 2,087 & 2,451 & $\begin{array}{l}2,445 \\
2,462 \\
2,453\end{array}$ & 2,464 & 0,200 & $\begin{array}{l}0,205 \\
0,208 \\
0,206\end{array}$ & 0,202 & 0,09 & $\begin{array}{l}0,09 \\
0,15 \\
0,09\end{array}$ & 0,08 \\
\hline 2,059 & $\begin{array}{l}2,054 \\
2,112 \\
2,098\end{array}$ & 2,098 & 2,456 & $\begin{array}{l}2,452 \\
2,460 \\
2,459\end{array}$ & 2,461 & 0,208 & $\begin{array}{l}0,211 \\
0,154 \\
0,170\end{array}$ & 0,191 & 0,12 & $\begin{array}{l}0,12 \\
0,49 \\
0,25\end{array}$ & 0,14 \\
\hline 2,107 & $\begin{array}{l}2,113 \\
2,170 \\
2,164 \\
2,172 \\
2,158 \\
2,160\end{array}$ & 2,163 & 2,456 & $\begin{array}{l}2,449 \\
2,438 \\
2,438 \\
2,436 \\
2,442 \\
2,434\end{array}$ & 2,459 & 0,160 & $\begin{array}{l}0,153 \\
0,065 \\
0,071 \\
0,070 \\
0,086 \\
0,075\end{array}$ & 0,119 & 0,38 & $\begin{array}{l}0,43 \\
0,97 \\
0,81 \\
0,87 \\
0,77 \\
0,82\end{array}$ & 0,58 \\
\hline 2,162 & $\begin{array}{l}2,157 \\
2,148 \\
2,148\end{array}$ & 2,194 & 2,437 & $\begin{array}{l}2,433 \\
2,445 \\
2,440\end{array}$ & 2,447 & 0,077 & $\begin{array}{l}0,091 \\
0,103 \\
0,111\end{array}$ & 0,062 & 0,78 & $\begin{array}{l}0,84 \\
0,65 \\
0,68\end{array}$ & 0,89 \\
\hline 2,147 & $\begin{array}{l}2,146 \\
2,009 \\
2,012\end{array}$ & 2,176 & 2,438 & $\begin{array}{l}2,434 \\
2,426 \\
2,392\end{array}$ & 2,446 & 0,101 & $\begin{array}{l}0,095 \\
0,195 \\
0,159\end{array}$ & 0,092 & 0,68 & $\begin{array}{l}0,70 \\
0,07 \\
0,26\end{array}$ & 0,73 \\
\hline 2,008 & $\begin{array}{l}1,997 \\
2,053 \\
2,151\end{array}$ & 2,063 & 2,410 & $\begin{array}{l}2,391 \\
2,421 \\
2,375\end{array}$ & 2,423 & 0,181 & $\begin{array}{l}0,172 \\
0,179 \\
0,074\end{array}$ & 0,196 & 0,16 & $\begin{array}{l}0,28 \\
0,23 \\
1,17\end{array}$ & 0,19 \\
\hline 2,101 & $\begin{array}{l}2,164 \\
2,151\end{array}$ & 2,089 & 2,399 & $\begin{array}{l}2,374 \\
2,445\end{array}$ & 2,428 & 0,128 & $\begin{array}{l}0,062 \\
0,091\end{array}$ & 0,168 & 0,71 & $\begin{array}{l}1,43 \\
0,70\end{array}$ & 0,35 \\
\hline 2,153 & $\begin{array}{l}2,157 \\
2,181 \\
2,181 \\
2,156\end{array}$ & 2,176 & 2,443 & $\begin{array}{l}2,439 \\
2,438 \\
2,430 \\
2,438\end{array}$ & 2,449 & 0,083 & $\begin{array}{l}0,070 \\
0,050 \\
0,034 \\
0,081\end{array}$ & 0,080 & 0,73 & $\begin{array}{l}0,79 \\
0,91 \\
0,99 \\
0,78\end{array}$ & 0,77 \\
\hline $\begin{array}{l}2,168 \\
2,167\end{array}$ & $\begin{array}{l}2,162 \\
2,167 \\
2,196\end{array}$ & $\begin{array}{l}2,201 \\
2,184\end{array}$ & $\begin{array}{l}2,435 \\
2,441\end{array}$ & $\begin{array}{l}2,431 \\
2,441 \\
2,437\end{array}$ & $\begin{array}{l}2,439 \\
2,441\end{array}$ & $\begin{array}{l}0,061 \\
0,065\end{array}$ & $\begin{array}{l}0,058 \\
0,065 \\
0,026\end{array}$ & $\begin{array}{l}0,041 \\
0,056\end{array}$ & $\begin{array}{l}0,86 \\
1,00\end{array}$ & $\begin{array}{l}0,85 \\
1,00 \\
1,67\end{array}$ & $\begin{array}{l}1,01 \\
0,92\end{array}$ \\
\hline 2,195 & 2,195 & 2,206 & 2,436 & 2,436 & 2,432 & 0,030 & 0,033 & 0,024 & 1,69 & 1,70 & 1,12 \\
\hline 2,010 & 2,010 & 2,054 & 2,375 & 2,375 & 2,371 & 0,172 & 0,017 & 0,187 & 0,38 & 0,38 & 0,48 \\
\hline 2,178 & $\begin{array}{l}2,178 \\
2,182\end{array}$ & 2,139 & 2,353 & $\begin{array}{l}2,353 \\
2,401\end{array}$ & 2,362 & 0,052 & $\begin{array}{l}0,052 \\
0,062\end{array}$ & 0,103 & 1,62 & $\begin{array}{l}1,62 \\
1,30\end{array}$ & 1,10 \\
\hline 2,176 & 2,179 & 2,207 & 2,413 & 2,412 & 2,385 & 0,065 & 0,061 & 0,044 & 1,19 & 1,21 & 1,46 \\
\hline
\end{tabular}

numbers for the 44-box model are ordered according to the corresponding box 10). The 19-box number specification is displayed in Figure 4. 

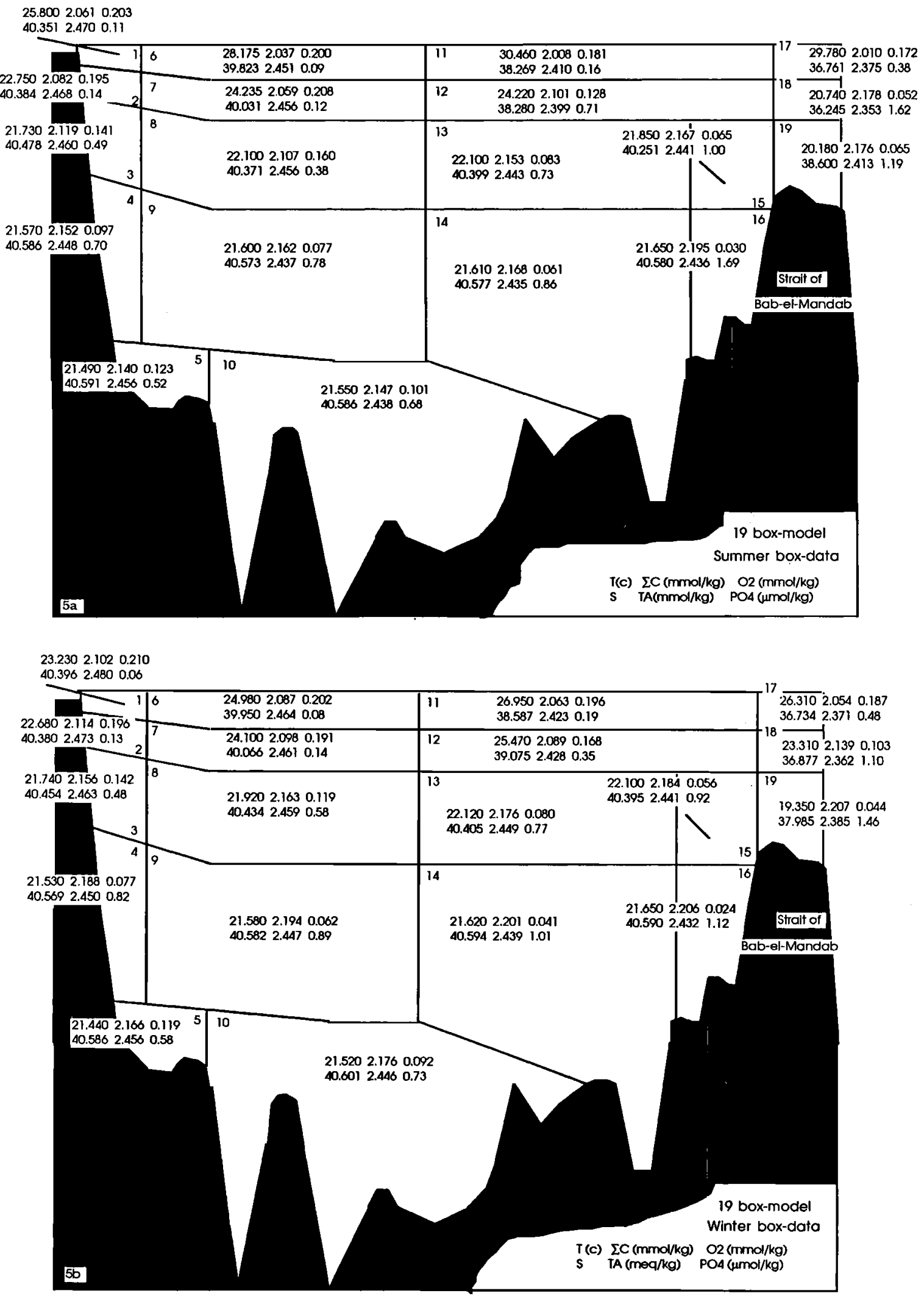
sedimentation (for $\mathrm{\Sigma C}, \mathrm{TA}, \mathrm{O}_{2}$ and $\mathrm{PO}_{4}$ ), and exchanges at the Bab-el-Mandab strait (for M, T, S, $\mathrm{CC}, \mathrm{TA}, \mathrm{O}_{2}$ and $\mathrm{PO}_{4}$ ).

2.3.1. Exchanges with the atmosphere $\left(M, T, \Sigma C\right.$ and $\left.\mathrm{O}_{2}\right)$.

The evaporation that is generally assumed for the Red Sea is $200 \mathrm{~cm} \mathrm{yr}^{-1}$ [e.g., Morcos, 1970]. This represents for the whole basin an annual mean loss of $0.03 \times 10^{6} \mathrm{~m}^{3} \mathrm{~s}^{-1}$. The seasonal values adopted are $0.035( \pm 0.003) \times 10^{6} \mathrm{~m}^{3} \mathrm{~s}^{-1}$ for summer and $0.025( \pm 0.003) \times 10^{6} \mathrm{~m}^{3} \mathrm{~s}^{-1}$ for winter.

The heat exchanges are calculated from the Climatic Atlas of the Indian Ocean [Hastenrath and Lamb, 1979]. The seasonal radiative budgets are the means over periods which are specific for summer (June to October) and winter (November to May) seasons.

The gas exchanges (tracers $\Sigma \mathrm{C}$ and $\mathrm{O}_{2}$ ) are estimated by flux calculations across the interface according to

$\Sigma \mathrm{C}$

$$
\mathrm{F}_{\Sigma \mathrm{C}, \mathrm{i}}=\Pi_{\Sigma \mathrm{C}} \mathrm{B}_{\Sigma \mathrm{C}} \Delta \mathrm{p}_{\Sigma \mathrm{C}} \mathrm{S}_{\mathrm{i}}
$$

$\mathrm{O}_{2}$

$$
\mathrm{FO}_{2, \mathrm{i}}=\prod_{\mathrm{O} 2} \Delta \mathrm{O}_{2} \mathrm{~S}_{\mathrm{i}}
$$

where $\mathrm{F}_{\Sigma \mathrm{C}, \mathrm{i}}$ (or $\mathrm{F}_{\mathrm{O} 2, \mathrm{i}}$ ) is the flux of $\mathrm{CO}_{2}$ (or $\mathrm{O}_{2}$ ) between the oceanic box $i$ and the atmosphere through the interface $S_{i}$; $\Pi_{\Sigma C}$ and $\Pi_{0} 2$ are the exchange coefficients (or piston velocity) which are a function of wind velocity, diffusion gas coefficient and sea surface temperature [Andrié et al., 1986; Liss and Merlivat, 1986]. The gas solubility for $\mathrm{CO}_{2}$ is $\mathrm{B}_{\Sigma \mathrm{C}} ; \Delta \mathrm{p} \Sigma \mathrm{C}$ is the difference of partial pressures of $\mathrm{CO}_{2}$, and $\Delta \mathrm{O}_{2}$ is the difference of $\mathrm{O}_{2}$ concentration between the atmosphere and the ocean. For summer we have used measured values of $\mathrm{CO}_{2}$ partial pressure in surface water and in the atmosphere [Beauverger et al., 1984a], whereas in winter we have used computed values (from TA and $\Sigma C$ titration) given by Weiss [1983] during the GEOSECS expedition. During both seasons partial pressures of carbon dioxide, as well as oxygen concentrations, are lower in the atmosphere than in the Red Sea. These gradients, at the air-sea interface, orient the fluxes from sea to atmosphere. That represents important information even if flux values are highly uncertain depending, in part, on the wind and temperature regimes. We do need, however, an order of magnitude for these exchanges which will be perturbed during model computations (perturbation on vector $B$ ).

2.3.2. Sedimentation ( $\Sigma \mathrm{C}, \mathrm{TA}, \mathrm{O}_{2}$ and $\mathrm{PO}_{4}$ ). There exist

few measurements of calcium carbonate $\left(\mathrm{CaCO}_{3}\right)$ sedimentation in the Red Sea. An estimation of 0.3 to $2 \mathrm{mg} \mathrm{cm}^{-2} \mathrm{yr}^{-1}$ of $\mathrm{CaCO}_{3}$ in the Red Sea is based on the spectrum of size distribution of particles in suspension [Beauverger et al., 1984a]. We will see that this value is too small to balance the annual budgets of $\mathrm{ZC}, \mathrm{TA}, \mathrm{O}_{2}$ and $\mathrm{PO}_{4}$ for the whole basin. The flux estimation based upon measurements of particles smaller than $40 \mu$ should be multiplied by a factor of 2 to 3 in order to include fluxes of particles of larger size [Brun-Cottan, 1986]. In addition, the computed data of Merou- $B$ [Beauverger et al., 1984al show that $\mathrm{CO}_{3}^{2-}$ (in situ) is higher than $\mathrm{CO}_{3}{ }^{2-}$ (sat) at each station and each depth. With these conditions, the dynamics of the carbonate system for the Red Sea is very different from those in oceans; in particular, large particles should play a more important role in the sedimentation fluxes. On the other hand, we need to consider not only the carbon losses (and hence, reduced oxygen import requirements) by sedimentation, but also the calcification rate which is even less well known. With such quantitative uncertainty, we have tested several sedimentation and calcification fluxes in determinig the overall budgets that we describe in the next subsection.

2.3.3. Exchanges at the Bab-el-Mandab strait. To complete the construction of the vector $B$, we now need to specify the exchanges at the strait of Bab-el-Mandab. There exist mass budget computations [e.g., Morcos, 1970] and direct measurements of currents [Maillard and Soliman, 1985] at this open ocean boundary. In terms of water budgets, these studies should be enough for the determination of the external water forcing in our model. Nevertheless, we need to establish an overall coherence in the determination of the external constraints with regard to a null annual budget for all tracers. For that, we construct a series of budget equations representative of compatible tracer budgets including all external processes. For $\mathrm{S}, \mathrm{T}, \mathrm{\Sigma C}, \mathrm{TA}, \mathrm{O}_{2}$ and $\mathrm{PO}_{4}$, we set an annual budget separating the different types of external exchanges as follows:

$$
\begin{aligned}
& t_{s}\left(-\sum_{a} F s_{q, a}+\sum_{d} F s_{q, d}\right)+t_{w}\left(-\sum_{a} F w_{q, a}+\sum_{d} F w_{q, d}\right)= \\
& t_{y} g_{q, o} F p_{q}+t_{y} g_{q, m} F p_{q}
\end{aligned}
$$

where $t_{s}, t_{w}$ and $t_{y}$ are the summer, winter and annual durations, $F s$ and $F w$ are the summer and winter exchanges of the tracer $q$ with the atmosphere (subscript a) or at the strait (subscript d). The sum $\Sigma_{\mathrm{a}}$ is over all boxes in contact with atmosphere and $\Sigma_{\mathrm{d}}$ for boxes at the strait of Bab-el-Mandab (Figure 6). $\mathrm{Fp}_{\mathrm{q}}$ is the sedimentation loss for the tracer $q$ in the whole basin, adjusted by the Redfield ratios $\mathrm{g}_{\mathrm{q}, \mathrm{o}}$ and $\mathrm{g}_{\mathrm{q}, \mathrm{m}}$ [Papaud and Poisson, 1986].

For mass (M), we uncouple the budgets of the two seasons (i.e., there is no net mass accumulation during each season):

$$
\begin{aligned}
& -\sum_{a} F s_{M, a}+\sum_{d} F s_{M, d}=0 \\
& -\Sigma_{a} F w_{M, a}+\sum_{d} F w_{M, d}=0
\end{aligned}
$$

Here, we are interested in resolving $\mathrm{Fs}_{\mathrm{M}, \mathrm{d}}$ and $\mathrm{Fw}_{\mathrm{M}, \mathrm{d}}$ so that (7b) and (7c) are compatible with equations (7a). We introduce

Fig. 5. (a) Summer box data $\left(q_{i}\right.$ in (4)) for $S, T, \Sigma C, T A, O_{2}$, and $\mathrm{PO}_{4}$ used for construction of matrix $A$ (in box 6 , mean temperature is $28.175^{\circ} \mathrm{C}$, salinity is 39.823 , dissolved inorganic carbon is $2.037 \mathrm{mmol} \mathrm{kg}^{-1}$, alkalinity is

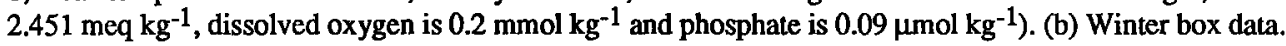



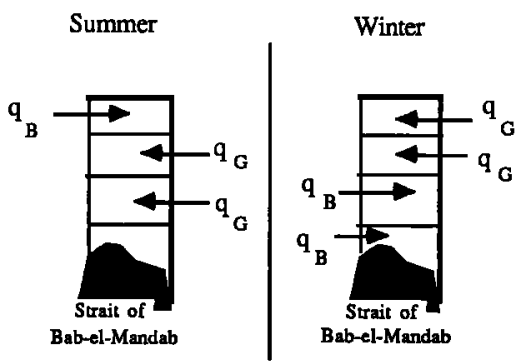

Seasonal Water Fluxes orientations Selection of $\mathrm{q}_{\mathrm{BG}}$

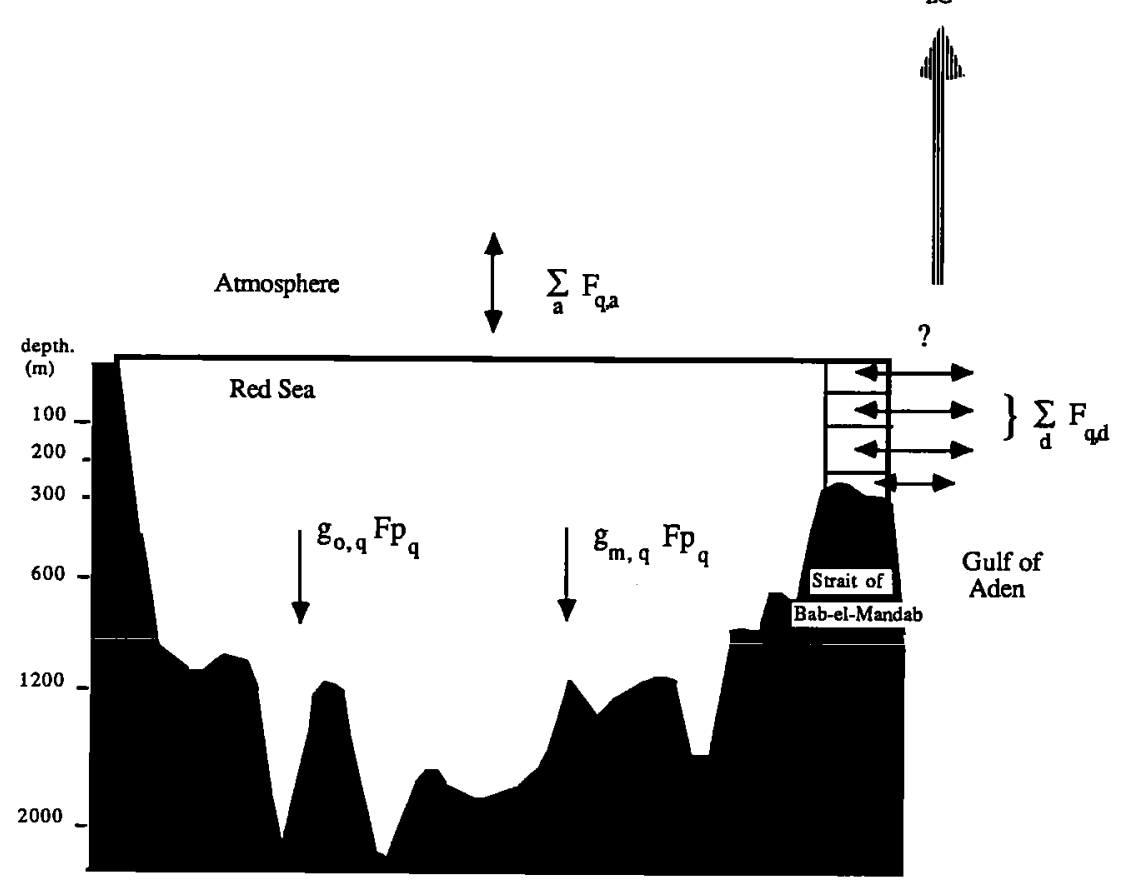

Fig. 6. Representation of parameters in system ((8a), (8b), (8c)). On the top, selection of quantity $\mathrm{q}_{\mathrm{BG}}\left(\mathrm{q}_{\mathrm{B}}\right.$ or $\left.\mathrm{q}_{\mathrm{G}}\right)$ depending on our a priori knowledge of transport orientation for each layer within the strait of Bab-el-Mandab.

these parameters in (7a), by decomposing the transport terms $\mathrm{Fs}_{\mathrm{q}, \mathrm{d}}$ and $\mathrm{Fw}_{\mathrm{q}, \mathrm{d}}$ :

$F s_{q, d}=F s_{M, d} \cdot q_{B G}$

$F w_{q, d}=F w_{M, d} q_{B G}$

where $q_{B G}$ is the quantity of the tracer $q$ in the basin $(B)$ or in the Gulf of Aden (G) depending on whether the water enters or exits the Red Sea. Even if we do not know the water mass fluxes through the strait well, we do know its seasonal orientation well [Morcos, 1970; Patzert, 1972; Maillard and Soliman, 1985], and we can select the quantity qBG for each box in contact with the boundary (Figure 6 ). We, then, rewrite the system ((7a),(7b),(7c)) describing the balance between budgets of tracers and mass due to the transport at the Bab-el-Mandab strait and those due to other external processes : $\mathrm{t}_{\mathrm{s}} \Sigma_{\mathrm{d}} \mathrm{Fs}_{\mathrm{M}, \mathrm{d}} \mathrm{qBG}_{\mathrm{B}}+\mathrm{t}_{\mathrm{w}} \Sigma_{\mathrm{d}} \mathrm{Fw}_{\mathrm{M}, \mathrm{d}} \mathrm{qBG}_{\mathrm{BG}}=$

$\mathrm{t}_{\mathrm{s}} \Sigma_{\mathrm{a}} \mathrm{Fs}_{\mathrm{q}, \mathrm{a}}+\mathrm{t}_{\mathrm{w}} \Sigma_{\mathrm{a}} \mathrm{Fw}_{\mathrm{q}, \mathrm{a}}+\mathrm{t}_{\mathrm{y}} \mathrm{gq}, \mathrm{o}_{\mathrm{o}} \mathrm{Fp}_{\mathrm{q}}+\mathrm{t}_{\mathrm{y}} \mathrm{gq}, \mathrm{m}_{\mathrm{m}} \mathrm{Fp}_{\mathrm{q}}$

$\Sigma_{\mathrm{d}} \mathrm{Fs}_{\mathrm{M}, \mathrm{d}}=\Sigma_{\mathrm{a}} \mathrm{Fs}_{\mathrm{M}, \mathrm{a}}$

$\sum_{\mathrm{d}} \mathrm{Fw}_{\mathrm{M}, \mathrm{d}}=\sum_{\mathrm{a}} \mathrm{Fw}_{\mathrm{M}, \mathrm{a}}$

If one has an estimation of the exchanges with the atmosphere (section 2.3.1) and of the sedimentation and calcification fluxes (section 2.3.2), then one can calculate (inversion of the system (8a), (8b) and (8c)) the water mass fluxes $\mathrm{Fs}_{\mathrm{M}, \mathrm{d}}$ and $\mathrm{Fw}_{\mathrm{M}, \mathrm{d}}$ which best satisfy the annual budgets of tracers. This computation has been performed, imposing bounded values on the unknowns ( $\mathrm{Fs}_{\mathrm{M}, \mathrm{d}}$ and $\mathrm{FW}_{\mathrm{M}, \mathrm{d}}$ ) and adjusting the total loss by sedimentation and calcification (term Fp). The bounded values have been taken from current measurements in the Bab-el-Mandab strait [Maillard and 
TABLE 2. External Exchanges for Each Tracer, Calculated From the System $((8 a),(8 b),(8 c))$

\begin{tabular}{|c|c|c|c|c|c|c|c|}
\hline & $\begin{array}{l}\mathrm{M} \\
10^{9} \mathrm{~kg}\end{array}$ & $\begin{array}{l}\mathrm{S} \\
10^{9} \mathrm{~g}\end{array}$ & $\begin{array}{c}\mathrm{T} \\
10^{12} \mathrm{~J}\end{array}$ & $\begin{array}{c}\Sigma \mathrm{C} \\
10^{9} \mathrm{mmol}\end{array}$ & $\begin{array}{c}\text { TA. } \\
10^{9} \mathrm{meq}\end{array}$ & $\begin{array}{c}\mathrm{O}_{2} \\
{ }^{9} \\
10^{\mathrm{mmol}}\end{array}$ & $\begin{array}{c}\mathrm{PO}_{4} \\
10^{9} \mu \mathrm{mol}\end{array}$ \\
\hline \multicolumn{8}{|c|}{ Summer } \\
\hline Strait. $\mathrm{s}^{-1}$ & 0.033 & 0.881 & -5.354 & 0.064 & 0.075 & -0.021 & 0.231 \\
\hline Atmosphere. $\mathrm{s}^{-1}$ & -0.033 & & 3.22 & -0.027 & & -0.038 & \\
\hline Sedimentation. $\mathrm{s}^{-1}$ & & & & -0.025 & -0.038 & 0.007 & -0.048 \\
\hline Budget, $10^{6}$ /summer & 0.000 & 11.65 & -28.2 & 0.483 & 0.493 & -0.676 & 2.419 \\
\hline \multicolumn{8}{|c|}{ Winter } \\
\hline Strait , $s^{-1}$ & 0.022 & -0.636 & 11.63 & 0.002 & 0.011 & 0.032 & -0.084 \\
\hline Atmosphere, $\mathrm{s}^{-1}$ & -0.022 & & -10.09 & -0.004 & & -0.002 & \\
\hline Sedimentation. $s^{-1}$ & & & & -0.025 & -0.038 & 0.007 & -0.048 \\
\hline Budget. $10^{6}$ /winter & 0.000 & -11.649 & 28.2 & -0.48 & -0.493 & 0.675 & -2.419 \\
\hline \multicolumn{8}{|c|}{ Year } \\
\hline Budget, $10^{6}$ /year & 0.000 & 0.001 & 0.00 & 0.003 & 0.000 & 0.000 & 0.000 \\
\hline
\end{tabular}

The time reference for the exchanges (strait, atmosphere, and sedimentation) is $1 \mathrm{~s}$. The budgets (summer, winter, and year) are referred to season and year.

Soliman, 1985] for summer and from literature for winter [Morcos, 1970]. The value of Fp which best balances the budgets ((8a),(8b),(8c)) is equivalent to $2.4 \mathrm{mg} \mathrm{cm}^{-2} \mathrm{yr}^{-1}$ of $\mathrm{CaCO}_{3}$. This is greater than the maximum measured value of $2 \mathrm{mg} \mathrm{cm}^{-2} \mathrm{yr}^{-1}$ and 8 times greater than the minimum of $0.3 \mathrm{mg} \mathrm{cm}^{-2} \mathrm{yr}^{-1}$ [Beauverger et al., 1984a]. Table 2 gives a summary of external exchanges calculated in this manner for the whole basin and for each tracer. Figure 7 presents annual budgets of $\Sigma \mathrm{C}, \mathrm{TA}, \mathrm{O}_{2}$ and $\mathrm{PO}_{4}$. Figures $8 \mathrm{a}$ and $8 \mathrm{~b}$ present, as examples, the exchanges of heat and dissolved inorganic carbon as they are imposed in the 19-box model.

\subsection{Convex Constraints: A Priori Information}

From one viewpoint, an aim of this study is to find the "best" compatibility between tracer budgets, represented by (4), and realistic rates of processes (unknowns) which govern those budgets. By realistic, we mean a physically meaningful number. In multibox models, it is often difficult to extract a physically meaningful solution from the inversion of system $\mathbf{A X}=\mathbf{B}$ alone. In part, this difficulty often arises when one asks too much from the data and/or one does not use all information (data) that one could. As a means of employing more information regarding what is known about the Red Sea, we will use "a priori" information by imposing a set of linear constraints, $\mathbf{G X} \geq \mathbf{H}$ (called convex constraints) representative of certain realistic solution limits. The set of our a priori knowledge defines a limit between feasible and infeasible solutions. For a mathematical description of these constraints see, for example, Menke [1984, pp. 126-131]; different classes of a priori information for oceanographic applications are described well by Wunsch [1984].

The limits on unknowns are the following: certain advective fluxes (for example, sinking of water in the north during winter) have an orientation or a minimal and maximal value imposed, $v_{i j} \geq v_{a}$ where $v_{a}$ is a reasonable lower limit; the eddy diffusivities are required to be nonnegative, $k_{\mathrm{ij}} \geq 0$ [Wunsch and Minster, 1982; Bolin et al., 1983]; for the biological processes, we impose nonpositive exchanges (organic, $\mathrm{co}_{i} \leq 0$, and mineral, 

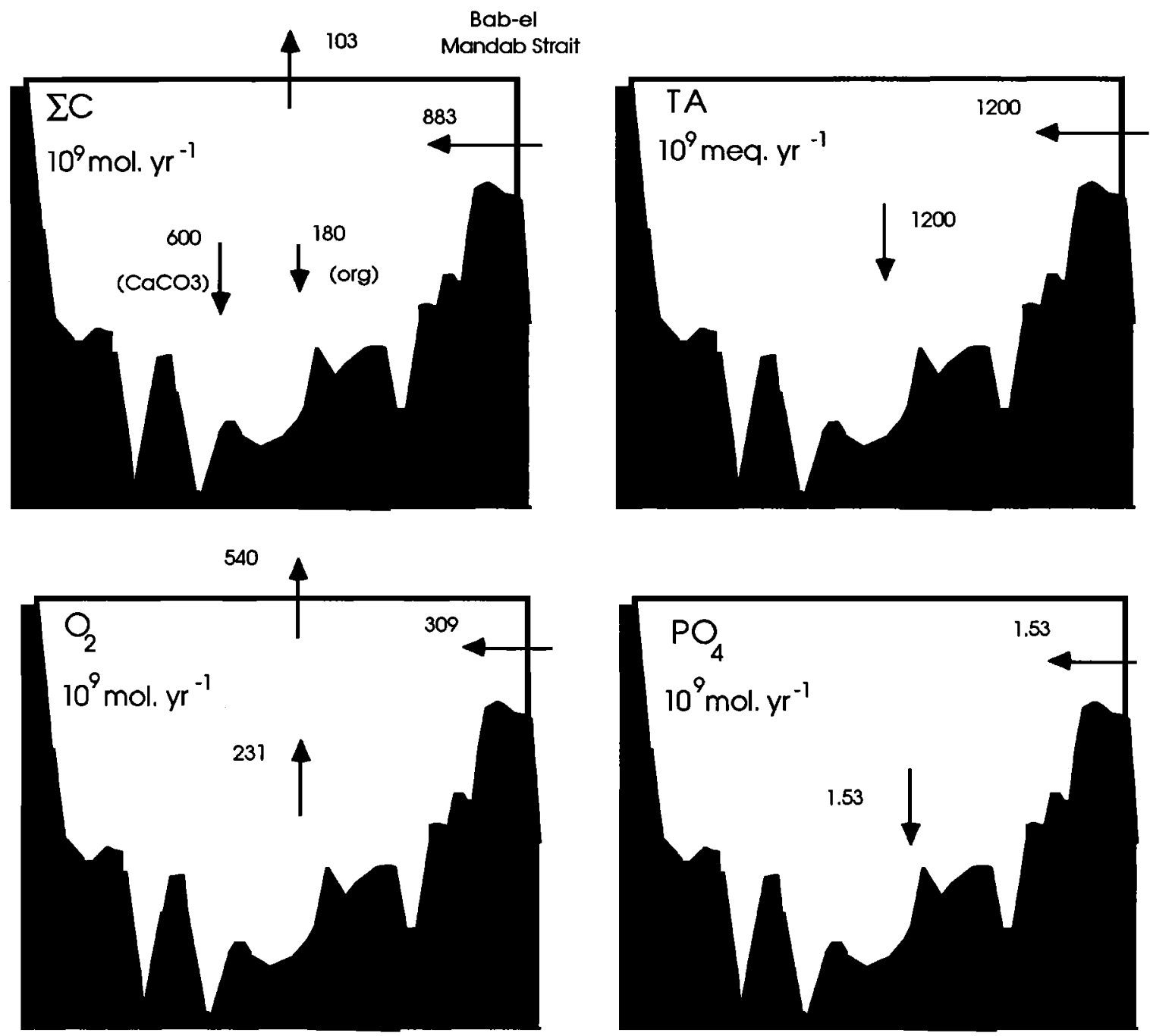

Fig. 7. Overall budget of $\Sigma \mathrm{C}, \mathrm{TA}, \mathrm{O}_{2}$ and $\mathrm{PO}_{4}$ as deduced by inversion of system ((8a), (8b), (8c)).

$\mathrm{cm}_{\mathrm{i}} \leq 0$ ) of dissolved carbon in the surface boxes (the production is greater than dissolution); in deep boxes, we impose the decomposition of the organic matter (nonnegative exchanges, $\mathrm{CO}_{\mathrm{i}} \geq 0$ ), but we do not constrain mineral exchanges. We have seen in 2.3.2., that the carbonate system in Red Sea is specific $\left(\mathrm{CO}_{3}{ }^{2-}{ }_{\text {(insitu) }}>\mathrm{CO}_{3}{ }^{2-}{ }_{\text {(sat) }}\right)$; we cannot assume a priori information about the degradation of mineral matter in intermediate and deep layers. These individual constraints are summarized in Figure 9.

In the 12-box model of the global ocean [Bolin et al., 1983; Garçon and Minster, 1988] or the 84-box model of the Atlantic Ocean [Bolin et al., 1987], geographic continuity constraints are imposed on the biochemical exchanges (i.e., the production in a surface box is exactly compensated by decomposition in boxes below). We know that transport of suspended matter is mainly due to horizontal advection [Brun-Cottan, 1986] and in the case of Red Sea, the spatial scale does not permit one to impose this geographically or column-specific production-decomposition continuity. Nevertheless, we could expect a balance between the biological processes (for all boxes) in the basin and the losses by sedimentation and calcification. This balance can be written for both organic and mineral exchanges as follows:

$\Sigma_{\mathrm{i}} \mathrm{co}_{\mathrm{i}}=\mathrm{fp}_{\mathrm{o}} \quad \sum_{\mathrm{i}} \mathrm{cm}_{\mathrm{i}}=\mathrm{fp}_{\mathrm{m}} \quad \mathrm{i}=1,2, \ldots, 19$

where $\mathrm{fp}_{\mathrm{o}}$ and $\mathrm{fp}_{\mathrm{m}}$ are the carbon losses by sedimentation and calcification. However, these equality constraints could impose a fictitious biological activity on the Red Sea. The basin is not closed, and there exist exchanges of living or dead particles, in the south of the Bab-el-Mandab surait (our hydrological boundary). There could be losses of carbon for the basin, especially during summer, when the wind imposes a flux of surface water (where production takes place) toward the Gulf of Aden. On the other hand, the budget of dissolved inorganic carbon, at the Bab-el-Mandab strait, is positive during summer and winter [Souvermezoglou, 1985; Souvermezoglou et al., 


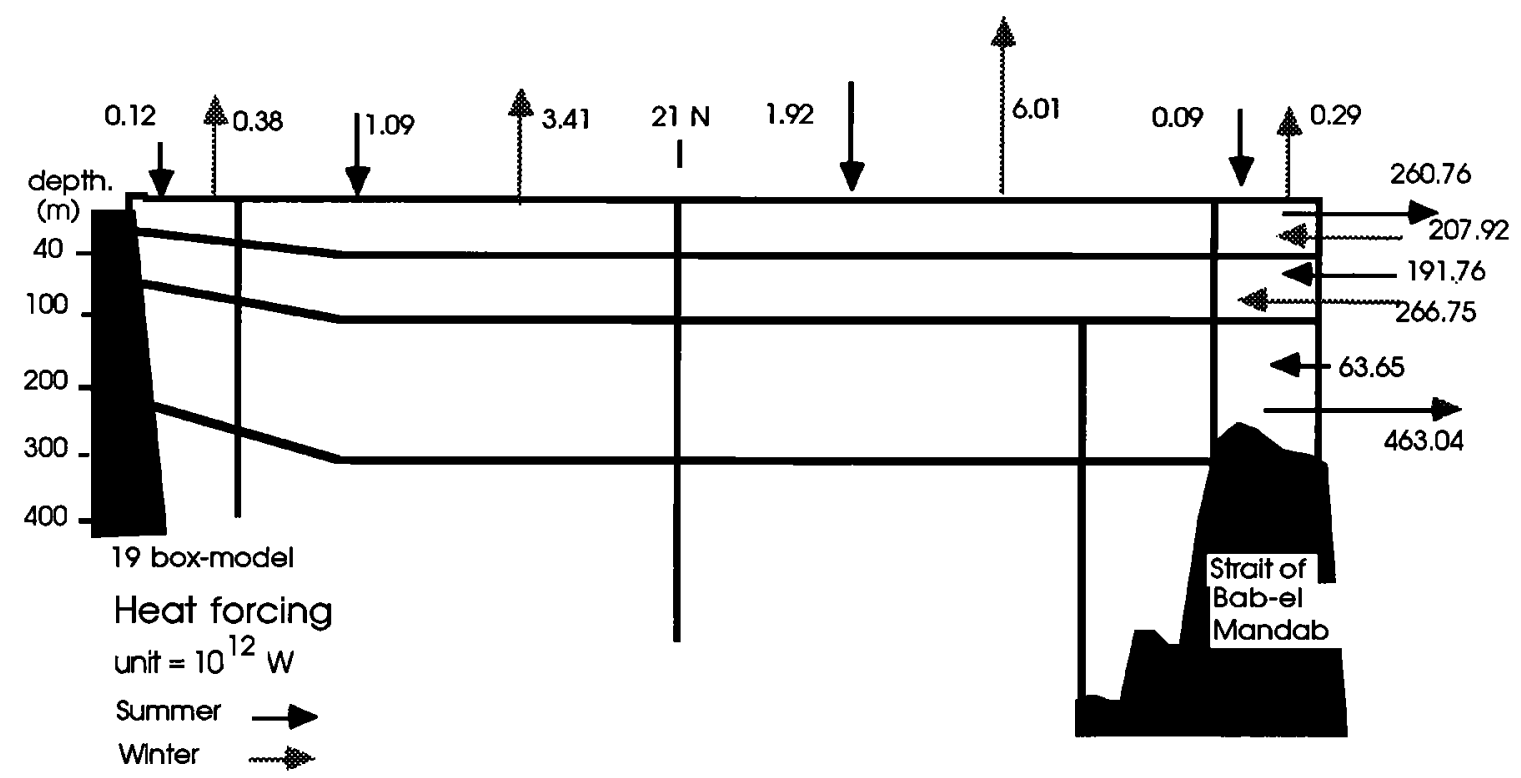

$8 \mathbf{a}$

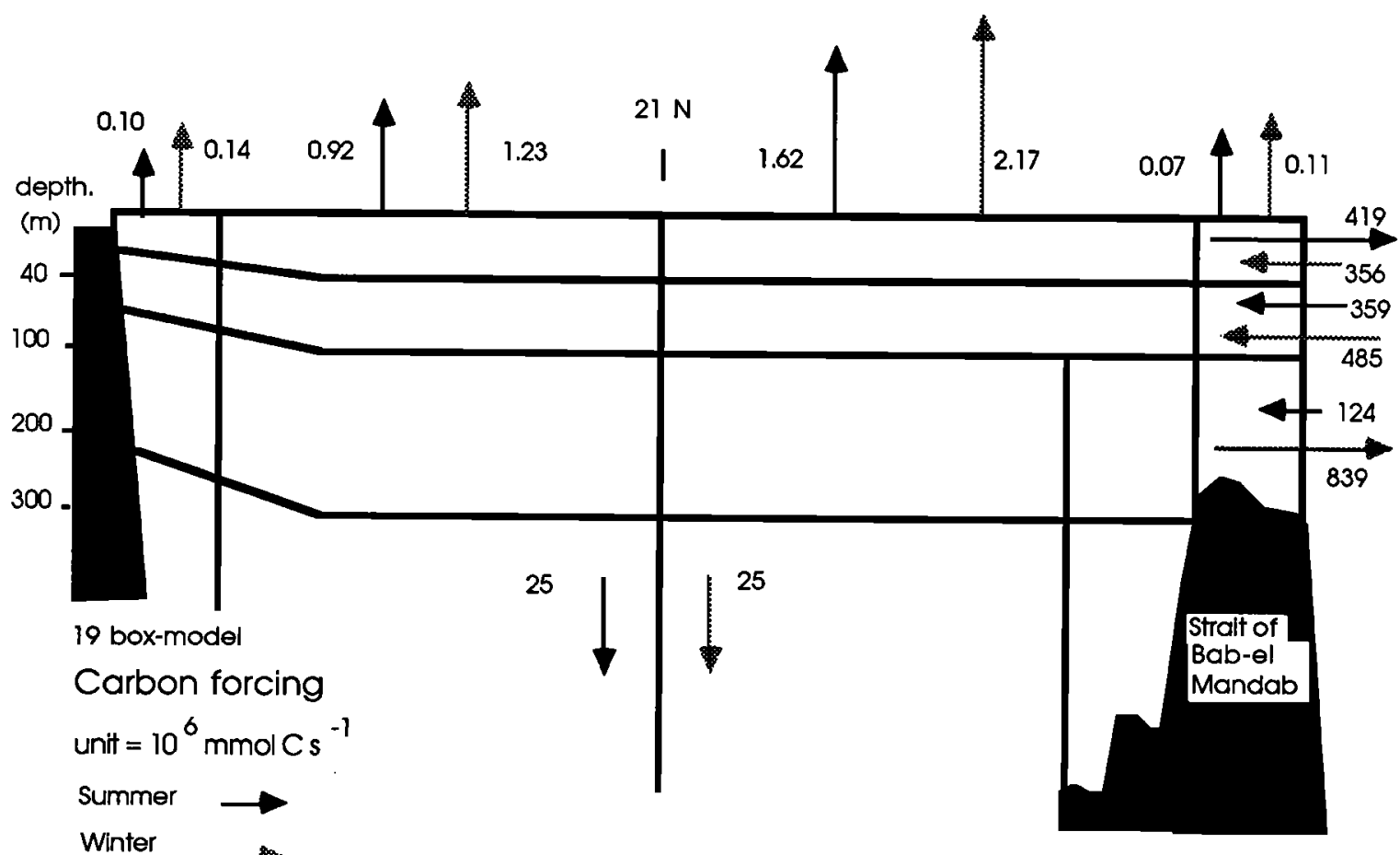

$8 b$

Fig. 8. External exchanges (19-box model) for summer and winter versions, for tracers (a) $\mathrm{T}$ in $10^{12} \mathrm{~W}$ and (b) $\Sigma \mathrm{C}$ in $10^{6} \mathrm{mmol} \mathrm{C} \mathrm{s}^{-1}$. Air-sea heat fluxes are opposite for winter and summer; air-sea carbon exchanges have the same orientation for both seasons. 


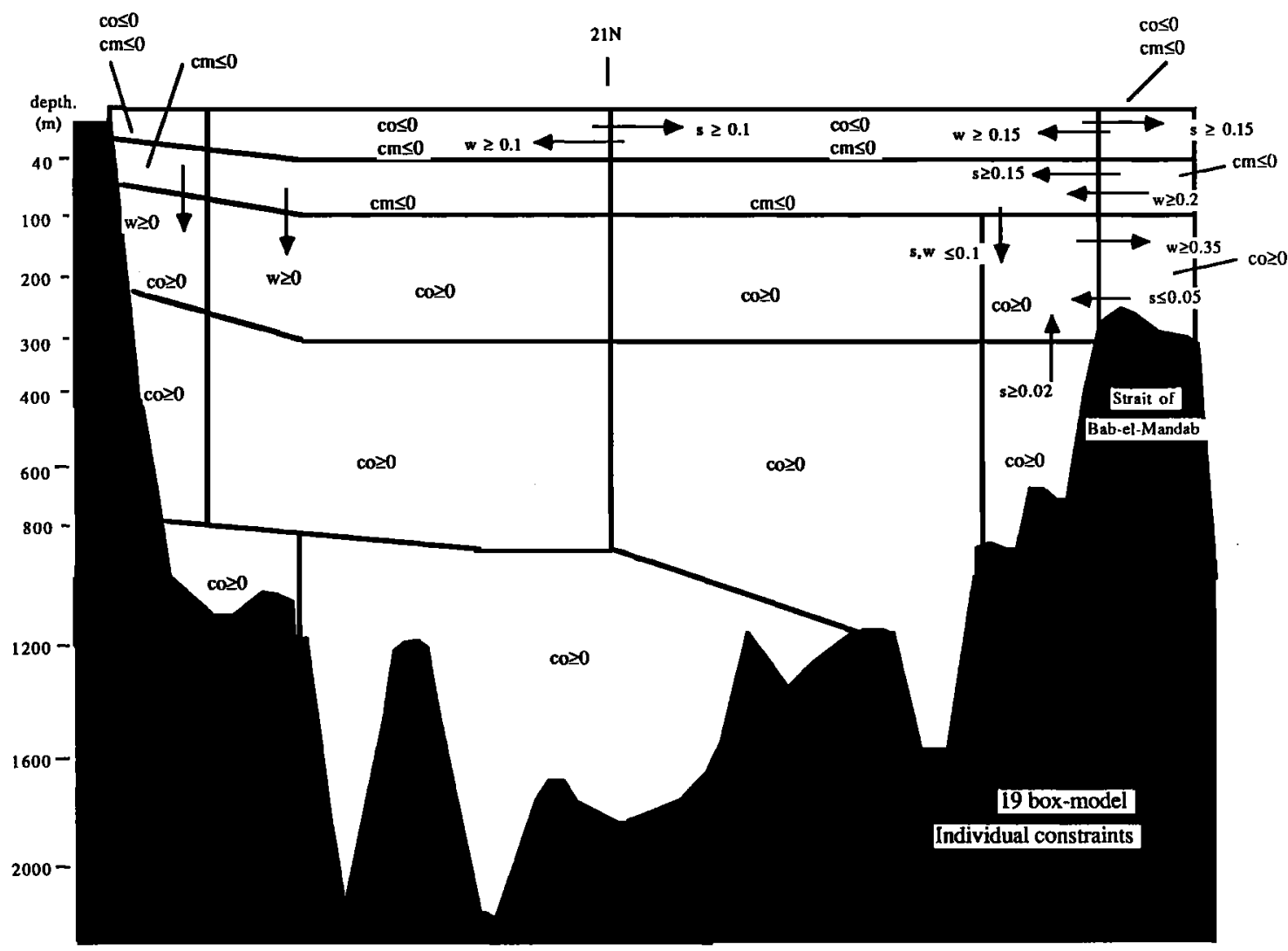

Fig. 9. Individual constraints imposed to unknowns. Symbol $s$ and $w$ denote summer and winter advective constraints (the arrows orient the flux and numbers are the limited value). Constraints on diffusion coefficient $\left(\mathrm{k}_{\mathrm{ij}} \geq 0\right.$ for each interface $i j$ ) are not represented in the figure.

1988]; the losses of carbon by exchanges with atmosphere are too small to compensate this positive budget (Souvermezoglou et al., 1988). Therefore, if we assume an annual equilibrated budget, then a loss of carbon, by sedimentation, calcification or other unknown processes, is needed within the basin. Since the terms $\mathrm{fp}_{\mathrm{o}}$ and $\mathrm{fp}_{\mathrm{m}}$ are not well known and since we want to avoid forcing a possibly fictitious process, we have adopted an inequality constraint, rather than imposing the equality constraint (9a). Specifically, we require that the sum of net biological activity over the whole basin be nonpositive :

$$
\sum_{\mathrm{i}} \mathrm{co}_{\mathrm{i}} \leq 0 \quad \sum_{\mathrm{i}} \mathrm{cm}_{\mathrm{i}} \leq 0 \quad \mathrm{i}=1,2, \ldots 19
$$

Applying the convex constraints (9b) rather than the equality equations (9a), the matrix $A$ of system (5) contains only the water continuity and tracer transport equations. The expressions (9b) dealing with net biological activity for the basin as a whole are carried in matrix $\mathbf{G}$.

\subsection{Noise in the Data: Sensitivity Studies}

In order to compute variance in solutions, we have applied random perturbations to both data and external forcings. For each tracer $\mathrm{q}$, the box data $\mathrm{q}_{\mathrm{i}}$ are perturbed by the product [ $\mathrm{r} \mathrm{eq} \mathrm{q}_{\mathrm{i}}$ ] where, $-1 \leq \mathrm{r} \leq 1$ is a random number and $\mathrm{eq}$ is the relative error of the tracer $q$ (we assume $\mathrm{q} q$ is the same in each box). We have imposed for $\mathrm{M}, \mathrm{S}, \mathrm{T}, \Sigma \mathrm{C}, \mathrm{TA}, \mathrm{O}_{2}$ and $\mathrm{PO}_{4}$ respectively 0.01 , $0.01,0.01,0.2,0.2,1$ and $1 \%$ of relative errors. We, then, construct matrix $A$ with these perturbed values. For the external forcings (vector B), we have tested perturbations of $10 \%$ or $20 \%$ for all elements of vector B; a perturbation depending on the confidence that we have for a specific tracer has also been performed (for instance, if we think we know the evaporation rates within a range of $10 \%$, and gas exchanges at the air-sea interface with $20 \%$ ). We have tested the response of the model to 10 and 20 random perturbations. The mean solutions of these different tests stay within the resolution limits (the differences of solutions are lower than the corresponding standard deviation). For each result presented in the next section the solutions of the system [(5),(6)\} are the means of 10 inversions corresponding to 10 random perturbations on box data (eq perturbation) and external exchanges ( $10 \%$ perturbation).

\section{RESULTS}

\subsection{The 19-Box Model}

In this section, we present the solutions for the 19-box versions, summer (S19a) or winter (W19a), obtained with the convex constraints and the perturbations described in sections 
2.4 and 2.5. Because we do not know a priori which tracer distribution contains the better information, we have chosen to apply the same weight for all of them except for water mass budgets. To insure that water continuity is better satisfied [see Bolin et al., 1983], a weight of 100 has been imposed on the water mass budgets. We have adopted this strong constraint in order to minimize the residues of mass budgets. By weighting water equations, the global residue of water is smaller by a factor of 15. For each inversion, the rank of $\mathbf{A}$ is full $(=100)$; all singular values are used to minimize the weighted norm $\left\|(\mathbf{A X}-\mathbf{B})_{\mathbf{W}}\right\|$. A singular value decomposition (SVD programming [Lawson and Hanson, 1974]), shows that the system is not ill-conditioned (Figure 10). The smallest singular value is greater than the tolerance of $10^{-7}$ we have imposed in the LSI code (the jump between 19 and 20 singular value corresponds to the 19 mass weighted equations), so there is no matrix truncation required and consequently the least squares programming LSI [Lawson and Hanson, 1974] uses all the information for solution determination.

The summer budgets are generally "better" resolved than the winter; the residual norm, $\|\mathbf{A X}-\mathbf{B}\|$, is about a third lower in the summer version than in winter (Table 3 ). One might think that the difference is due to the different amount of information (10 stations used for summer, against three for winter); however, there is no direct justification for this conclusion. By looking at the tracer residues, we find that the equations for $\mathrm{M}$, $\Sigma \mathrm{C}, \mathrm{TA}, \mathrm{O}_{2}$, and $\mathrm{PO}_{4}$ are chiefly responsible for this "better" resolution; the residues $\|A(q) X-B(q)\|$ for each tracer $M, \Sigma C$, $\mathrm{TA}, \mathrm{O}_{2}$, and $\mathrm{PO}_{4}$, are smaller in version $\mathrm{S} 19 \mathrm{a}$ than in $\mathrm{W} 19 \mathrm{a}$, whereas the residues on the heat and salt budgets have the same order of magnitude for the two seasons (Table 3). It is important to note that budgets of tracers $\Sigma \mathrm{C}, \mathrm{TA}, \mathrm{O}_{2}$, and $\mathrm{PO}_{4}$, contain the two dynamic processes (unknowns $v_{\mathrm{ij}} \mathrm{s}_{\mathrm{ij}}$ and $\left.\mathrm{k}_{\mathrm{ij}} \mathrm{s}_{\mathrm{ij}} / \mathrm{D}_{\mathrm{ij}}\right)$ and at least one biochemical exchange $\left(\mathrm{co}_{\mathrm{i}}\right.$ or $\mathrm{cm}_{\mathrm{i}}$, or both), while the tracers $S$ and $T$ are only involved in the dynamical exchanges. We shall see, in the description of the results, that the biochemical exchanges are not well resolved for the winter season. That seems to explain the better overall budgets of $\Sigma \mathrm{C}, \mathrm{TA}, \mathrm{O}_{2}$, and $\mathrm{PO}_{4}$ in summer with regard to the winter solutions.

Figures 11a and 12a present the advective solutions for the summer and winter, respectively. In the surface, the flow regime is reversed from one season to the other, and the circulation loop in the north of the basin characterizes divergence (in summer) and convergence systems (in winter). The diffusion (not presented in figures) is localized principally at the surface and subsurface interfaces, characterizing the mixing processes between the Red Sea waters and the new water from the Gulf of Aden. The subsurface flux (40-100 m) in the center of the basin maintains the same orientation, toward the south, and is of the same order of magnitude: $0.14( \pm 0.01) \mathrm{Sv}$ ( $\left.1 \mathrm{~Sv}(1 \mathrm{Sverdrup})=10^{6} \mathrm{~m}^{3} \mathrm{~s}^{-1}\right)$ in winter, $0.12( \pm 0.03) \mathrm{Sv}$ in summer. In summer this flux participates with a part of incoming water (40-100 $\mathrm{m}$ ) from the Gulf of Aden, forming a source of deep water (through the 100-m interface). The subsurface water coming from the Gulf of Aden, colder and less saline than Red Sea water, keeps its properties in the strait and in southern portion of basin, even if it supports a mixing through the strait. This situation is well illustrated in the potential temperature-salinity (Figure 13a) or $\mathrm{\Sigma C}$-salinity
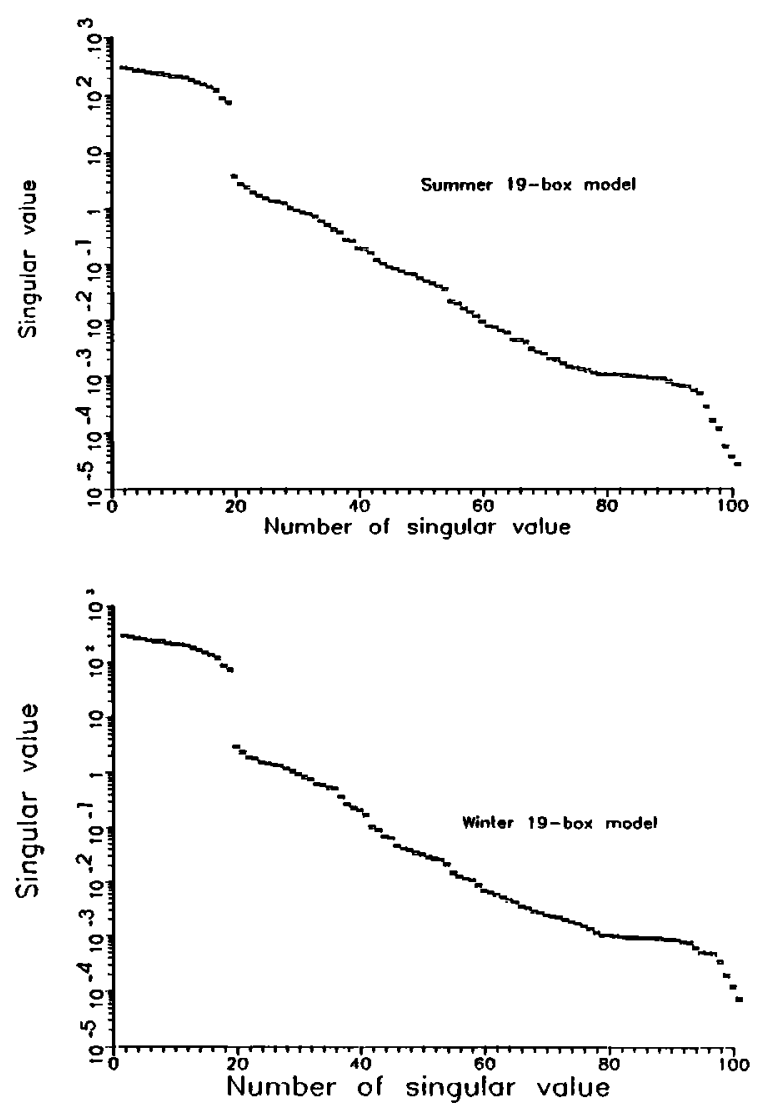

Fig. 10. Singular values decomposition of matrix $\mathbf{A}$ for summer (top) and winter (bottom) applications. The first 19 values correspond to the upweighted mass equations.

(Figure 13b) diagrams for the summer data, where we can identify the Aden water end-member at stations 139,143, and 145 (the station positions are specified in Figure 4). At station 149 , this situation is less marked; the Aden waters lose their hydrological and biochemical characteristics, gain salinity and temperature, and become denser north of the strait. From station 153 , in the middle of Red Sea, there is no signal of Aden water.

The tracer distribution clearly orients the solutions: in the southern part of Red Sea, at the 100-m interface, the model presents, for both seasons, a downward advective process, 0.17 $( \pm 0.02) \mathrm{Sv}$ in summer, and $0.33( \pm 0.03) \mathrm{Sv}$ in winter, which balances the inflow from Aden and the southward flow at latitude $21^{\circ} \mathrm{N}$. By contrast, above $100 \mathrm{~m}$, the advective solution is seasonally different. During winter, the flow between 100 and $300 \mathrm{~m}$ is directed northward $(0.45( \pm 0.04) \mathrm{Sv})$, while during summer, the greatest outflow from subsurface waters is downward $(0.19( \pm 0.01) S v)$. Therefore, the deep advective solution is reversed. Thompson [1939] had suggested the possibility of seasonal inversion of a dynamical system, characterizing a pivoting circulation in a vertical plane, about a point lying at $\left(320 \mathrm{~m}, 19^{\circ} \mathrm{N}\right)$. In Thompson's scheme the water motion situated about $\left(450 \mathrm{~m}, 23^{\circ} \mathrm{N}\right)$ is directed southward in winter, northward in summer with the central region remaining near an annual steady state regime. We can not define an equivalent pivoting point, but the 19-box model solutions 
TABLE 3. Residue (time, $10^{-5} \mathrm{~m}^{3} \mathrm{~s}^{-1}$ ) of the Weighted System $\left\|(\mathbf{A X}-\mathbf{B})_{W}\right\|$, of the Difference Between Right and Left Sides $\| \mathbf{A} X-B||$, and Tracer Equations || $\mathbf{A}_{\mathbf{q}} \mathbf{X}-\mathbf{B}_{\mathbf{q}} \|$, (with $\mathrm{q}=\mathrm{M}, \mathrm{S}, \mathrm{T}, \mathrm{\Sigma C}, \mathrm{TA}, \mathrm{O}_{2}$ and $\mathrm{PO}_{4}$ )

\begin{tabular}{lllll}
\hline & \multicolumn{4}{c}{ RESIDUE } \\
\cline { 2 - 5 } & S19a & W19a & W19b & S44a \\
\hline$\left\|(\mathbf{A X}-\mathrm{B})_{\mathrm{w}}\right\|$ & 3.370 & 5.500 & 5.400 & 2.540 \\
$\|\mathbf{A ~ X - B}\|$ & 1.160 & 1.453 & 1.334 & 1.065 \\
$\mathrm{M}$ & 0.030 & 0.050 & 0.050 & 0.022 \\
$\mathrm{~S}$ & 0.368 & 0.418 & 0.420 & 0.312 \\
$\mathrm{~T}$ & 0.417 & 0.456 & 0.456 & 0.353 \\
$\Sigma \mathrm{C}$ & 0.246 & 0.377 & 0.373 & 0.260 \\
$\mathrm{TA}$ & 0.197 & 0.266 & 0.266 & 0.182 \\
$\mathrm{O}_{2}$ & 0.383 & 0.669 & 0.349 & 0.362 \\
$\mathrm{PO}{ }_{4}$ & 0.890 & 1.032 & 1.030 & 0.824 \\
\hline & & & & \\
\hline
\end{tabular}

corroborate a seasonally inverted circulation scheme not only in surface (due to the reversal of the wind stress), but also in the deep basin, around the $21^{\circ} \mathrm{N}$ interface (our central separation). As we shall see with the 44-box model, this reversal situation seems to be too extreme in the 19-box version, driven by a discretization scheme which smooths the tracer gradients.

In the winter version, we also obtain a characteristic solution for the deep layers. The deep water flux maintains the central basin (recirculation loop) and the exit at the strait of Bab-el-Mandab by upwelling of $0.25( \pm 0.11) \mathrm{Sv}$ in the south of basin. This response is in agreement with studies based on theoretical considerations and hydrodynamic calculations [Phillips, 1966; Grasshoff, 1969; Maillard, 1972; Manins, 1973; Morcos and Soliman, 1974; Wyrtki, 1974]. On the other hand, the formation of deep water in the northem portion of the basin, originally from a cascading at the Gulf of Suez exit [Maillard, 1974] is not well-represented in the model. We obtain a slight signal, $0.018( \pm 0.01) \mathrm{Sv}$ of the downwelling process, during winter, at the $100-\mathrm{m}$ interface. This flux is 20 times weaker than the flux of $0.45( \pm 0.04) \mathrm{Sv}$ from the south and participates weakly in the deep circulation. It is important to note that the model gives a seasonal description of the exchanges (we have assumed a seasonal steady state budget), and it must partially answer to new deep water formation processes which take place during three months, from February to April [Morcos, 1970]. However, the wintry slope of $0.018( \pm 0.01)$ Sv is close to the conclusions of Kuntz [1985]. Kuntz derived a flux of new deep water ( $0.008 \mathrm{~Sv}$ to $0.024 \mathrm{~Sv}$ ) by using the filling-box model of Manins [1973] adjusted by salinity and helium-tritium data. In our study and in the work of Kuntz [1985], this new deep water flux is weaker than the internal recirculation. Finally, in the northern deep layers, our solutions present, for both seasons, an advective loop that is opposite to the internal regime: the deep flux, $0.12( \pm 0.02) \mathrm{Sv}$, is northward during winter, while the summer solution, $0.03( \pm 0.02) \mathrm{Sv}$, shows a southward tendency.

All the production-consumption solutions of dissolved carbon are presented in Figures $11 \mathrm{~b}$ and $12 \mathrm{~b}$. About half of those solutions are resolved (the value is larger than the standard deviation). In the surface boxes, the organic and mineral productions are all greater than dissolutions (negative exchanges). This net production is stronger during summer and in the southern portion of the basin, reflecting the large importation of nutrients from the Gulf of Aden between June and September [Khimitsa and Bibik, 1979; Souvermezoglou, 1985; Naqvi et al., 1986]. However, during winter, in the surface, the organic production-consumption reaches a limit constraint $\left(\mathrm{CO}_{\mathbf{i}}=0\right)$, possibly directed by large dissolved carbon concentrations. A nonnegligible loss of dissolved carbon takes place in the north, during the two seasons (layer 40-100 m), which corresponds to an upwelling region (see Figures 11a and 12a), and the importation of nutrients. By contrast, at the same level in the southern part of basin, there is a rapid dissolution of organic material (gain of dissolved carbon). This degradation proceeds perhaps from the importation of particles formed in the Gulf of Aden, especially during winter [Beckmann, 1984]. Beyond $100 \mathrm{~m}$, which roughly corresponds to the bottom of the euphotic zone [Thiel and Weikert, 1984], the dissolution is greater than production (positive exchanges). The organic dissolution is well-characterized in the $300-1000 \mathrm{~m}$ layer during winter, whereas these exchanges reach the imposed constraint $\left(\mathrm{CO}_{\mathrm{i}}=0\right)$ for the summer version. This response is not surprising with regard to the high degradation of organic matter in upper layers of the Red Sea [Thiel and Weikert, 1984].

For the summer season, the total loss $\left(\Sigma_{\mathrm{i}} \mathrm{co}_{\mathrm{i}}\right.$ and $\Sigma_{\mathrm{i}} \mathrm{cm}_{\mathrm{i}}$, $i=1,2, \ldots, 19)$ of carbon by biochemical processes is $-0.35( \pm 0.05) \times 10^{8} \mathrm{mmol} \mathrm{C} \mathrm{s}^{-1}$ for the exchanges with the organic matter and $-0.54( \pm 0.14) \times 10^{8} \mathrm{mmol} \mathrm{C} \mathrm{s}^{-1}$ with the mineral. For the season, the organic and mineral activities

Fig. 11. Nineteen-box model solutions for summer (S19a). (a) Advection solutions in $10^{6} \mathrm{~m}^{3} \mathrm{~s}^{-1}$ (or sverdrups). The double arrows signal unresolved solutions (standard deviation larger than mean solution). Water forcing terms are also specified at the domain boundaries (atmosphere and Bab-el-Mandab strait). (b) Net exchanges of total inorganic carbon with organic matter (upper number and corresponding deviation) and mineral matter (lower number and corresponding deviation) within each box. Unit in $10^{6} \mathrm{mmol} \mathrm{C} \mathrm{s}^{-1}$. 

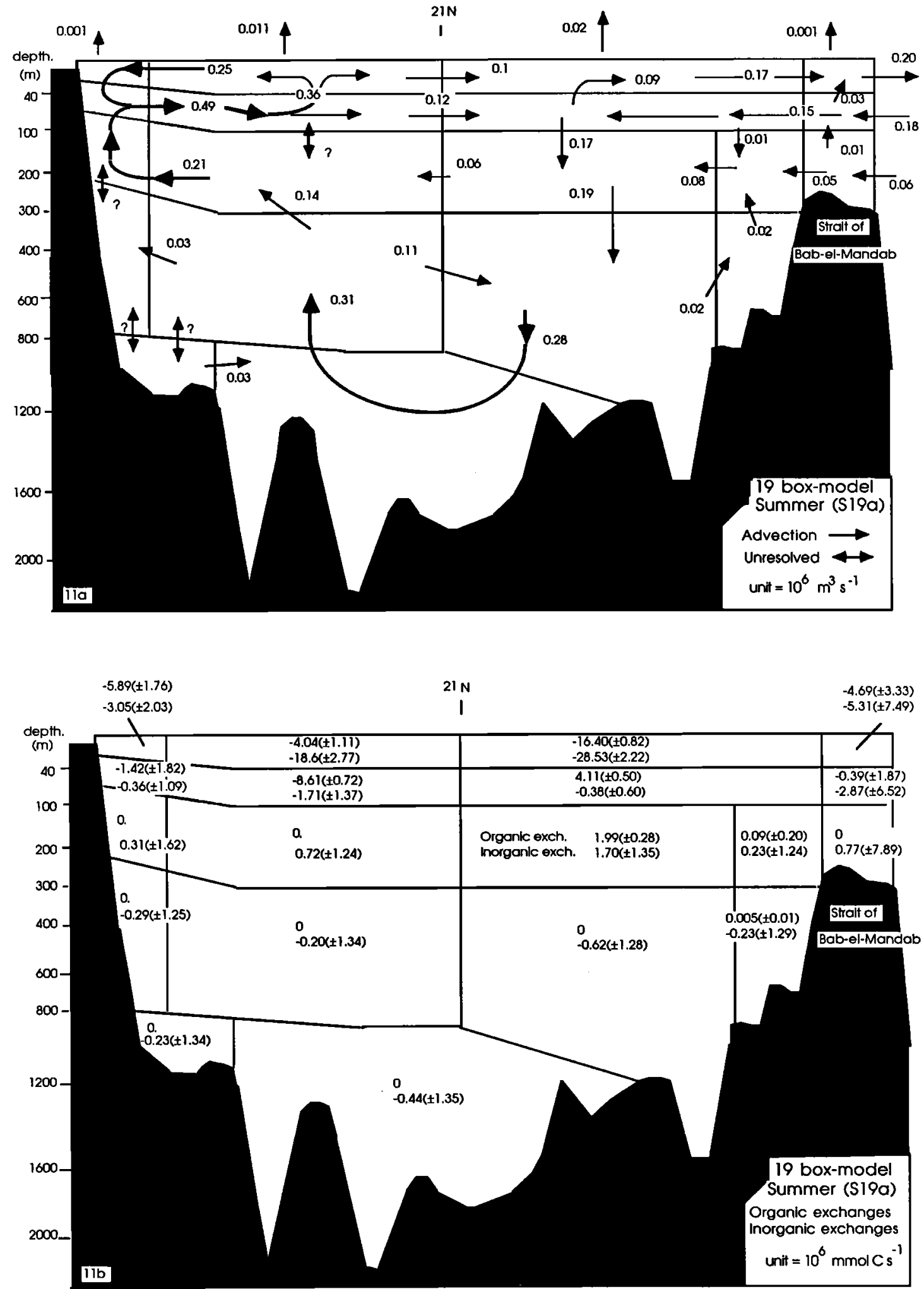

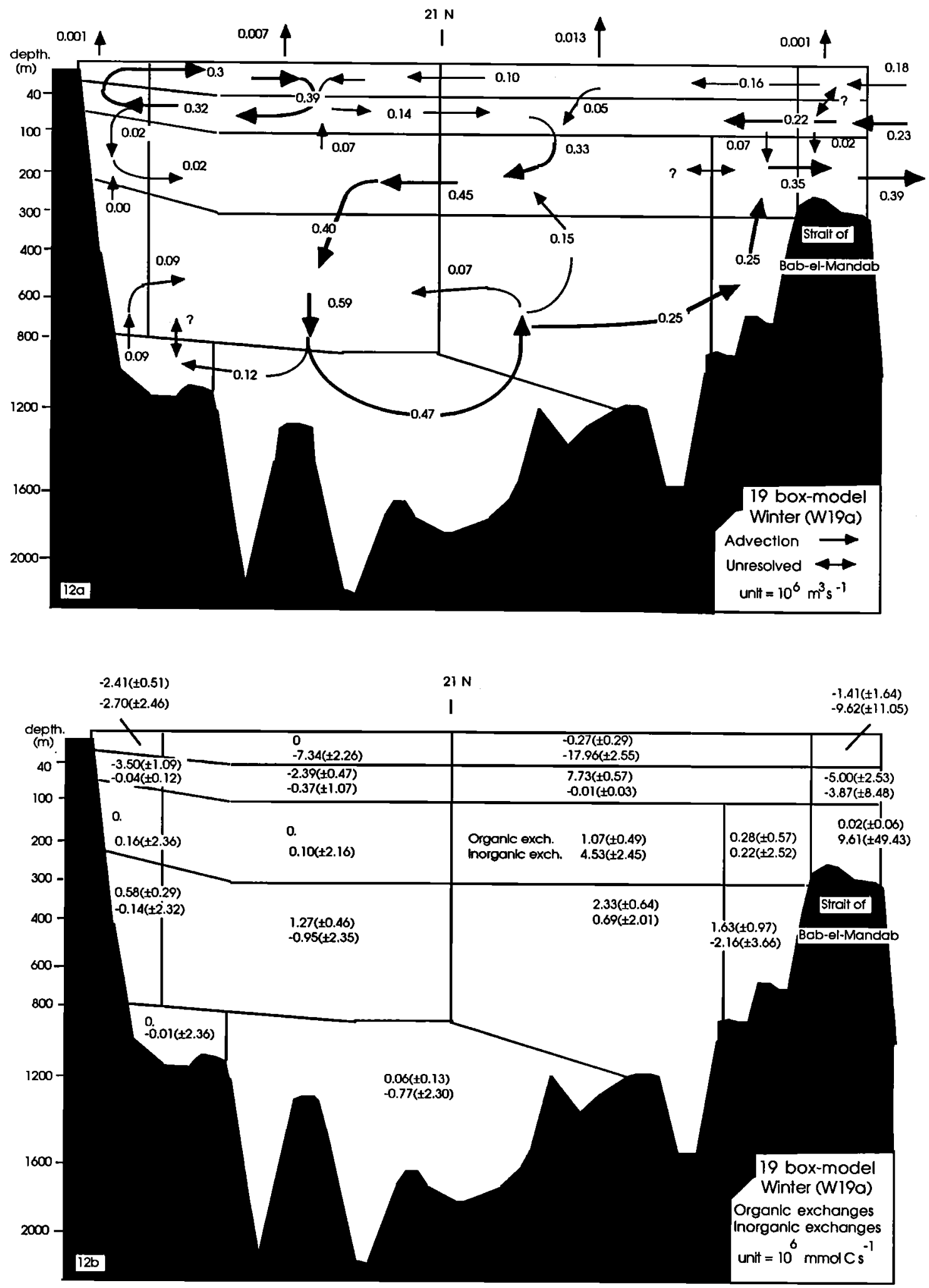

Fig. 12. Same as Figure 11 for winter (W19a). 
Merou-B (Oct. 1982)

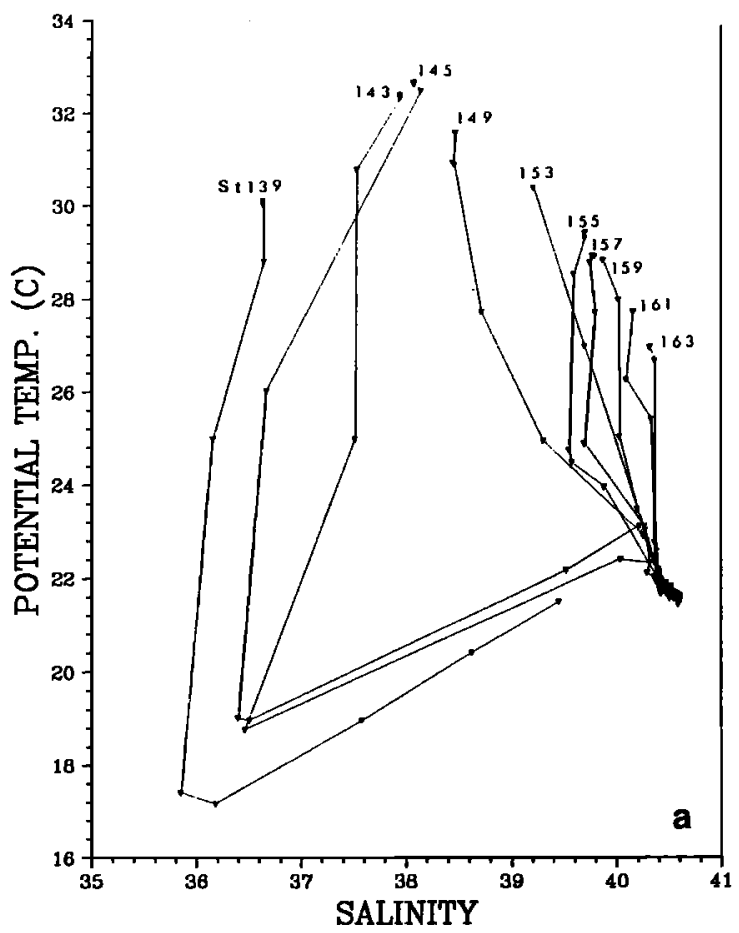

Merou-B (Oct. 1982)

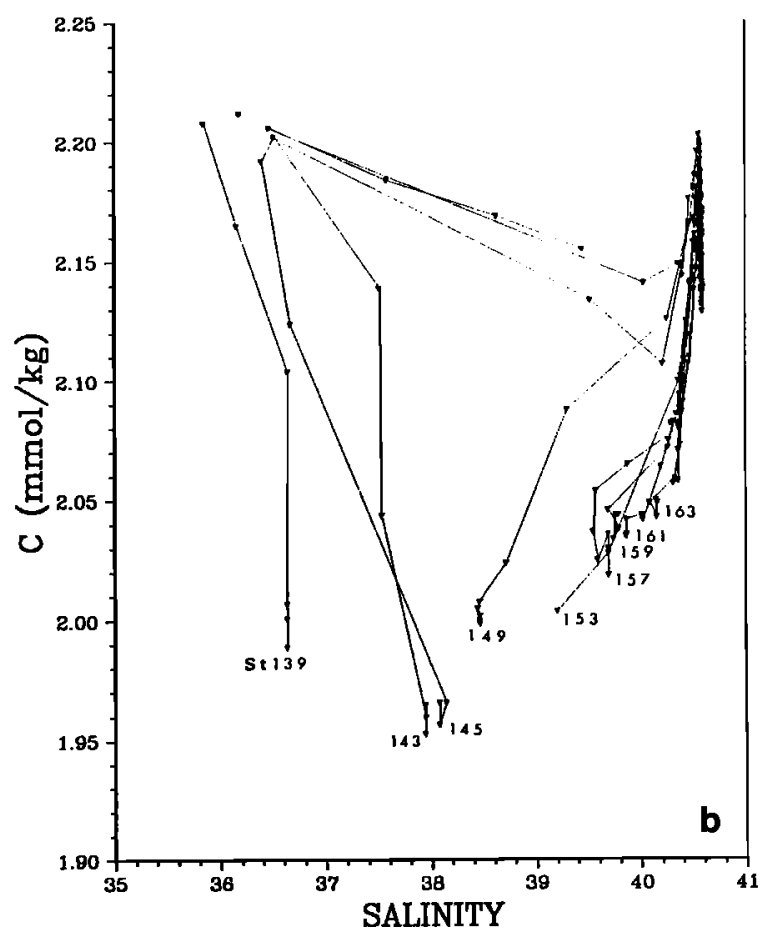

Fig. 13. (a) Potential temperature (T) versus salinity $(S)$, and (b) total inorganic carbon $(\Sigma C)$ versus salinity (S) diagrams for the stations $139,143,145,149,153,155,157,159,161$ and 163 (Merou-B expedition).

represent an overall loss of $-1.18( \pm 0.19) \times 10^{15} \mathrm{mmol} \mathrm{C}$ summer-1. During winter, the organic exchanges hit the limit of $\Sigma_{\mathrm{i}} \mathrm{co}_{\mathrm{i}}=0$ (we have imposed $\Sigma_{\mathrm{i}} \mathrm{co}_{\mathrm{i}} \leq 0, \mathrm{i}=1,2, \ldots, 19$ ), and it is not possible to draw any conclusions on the total amount of carbonate exchanges $\left(\Sigma_{\mathrm{i}} \mathrm{cm}_{\mathrm{i}}=-0.31( \pm 0.54) \times 10^{8} \mathrm{mmol} \mathrm{C} \mathrm{s}^{-1}\right.$, for $i=1, \ldots, 19)$. We have done the inversion without imposing the biochemical constraints on the whole basin $\left(\Sigma_{\mathrm{i}} \mathrm{Co}_{\mathrm{i}} \leq 0\right.$ and $\left.\Sigma_{\mathrm{i}} \mathrm{cm}_{\mathrm{i}} \leq 0, \mathrm{i}=1,2, \ldots, 19\right)$, but maintaining the individual constraints ( $\mathrm{CO}_{\mathrm{i}} \leq 0$ and $\mathrm{cm}_{\mathrm{i}} \leq 0$ ). The summer solutions are exactly the same; in this version, equations (4) in section 2.1, for the tracers $\Sigma \mathrm{C}, \mathrm{TA}, \mathrm{O}_{2}$, and $\mathrm{PO}_{4}$ orientate the biochemical processes; the constraints ( $9 \mathrm{~b})$ are not necessary. On the other hand, the new winter solution (W19b) is quite different (Figures $14 \mathrm{a}$ and 14b) from the base case version (W19a, Figures 12a and 12b). Compared to the first version (winter with constraint (9b)), the residues of the system and for each tracer (Table 3) are the same, except for the tracer $\mathrm{O}_{2}$, which is lower. Therefore, in the W19a version, one can say that the budgets (4) of oxygen are not compatible with the convex constraints $(9 \mathrm{~b})$. The new organic exchange configuration (Figure 14b) is characterized by a reduction of new production (null in surface) and an augmentation of dissolution.

In contrast to these changes in organic biochemical processes, the advective, diffusive and mineral exchanges are not much different. For the whole basin, we gain dissolved carbon, 0.21 $( \pm 0.06) \times 10^{8} \mathrm{mmol} \mathrm{C} \mathrm{s}^{-1}$ (null in W19a) by organic exchanges, but the overall mineral exchange is still unresolved,
$-0.32( \pm 0.52) \times 10^{8} \mathrm{mmol} \mathrm{C} \mathrm{s}^{-1}$. This unresolution could be removed, if we do not consider the exchanges within boxes in the strait, which depend strongly on the external perturbations (variance of solutions are large, see Figures $11 \mathrm{~b}$ and $12 \mathrm{~b}$ ). Here, we sum the exchanges $\mathrm{co}_{\mathrm{i}}$ and $\mathrm{cm}_{\mathrm{i}}$ over the first 16 boxes and we obtain for the internal basin itself (i.e., without considering the strait of Bab-el-Mandab) a gain of $0.46( \pm 0.09) \times 10^{15} \mathrm{mmol}$ $\mathrm{C}$ winter ${ }^{-1}$ by exchange with organic matter and a loss of

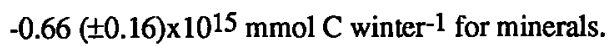

For the year, the inversion gives a balance for the carbon in the organic system of $-0.006( \pm 0.011) \mathrm{g} \mathrm{C} \mathrm{m}^{-2} \mathrm{~d}^{-1}$. This annual average of new production estimation in Red Sea is about 3\% of mean primary production of $0.21 \mathrm{~g} \mathrm{C} \mathrm{m}^{-2} \mathrm{~d}^{-1}$ given by Wyrtki [1974, Yentsch C. S. and L. Wood, Measurements of the primary production of the Red Sea, The Woods Hole Ocean. Inst., 61-6, App. B] or $6 \%$ of the limit of phytoplanktonic production, $0.100 \mathrm{~g} \mathrm{C} \mathrm{m}^{-2} \mathrm{~d}^{-1}$, proposed by Thiel and Weikert [1984]. Although, the carbon exchange with organic matter is "nonsignificant" (standard deviation larger than new production itself), the order of magnitude is reasonable (i.e., it is not greater than $10 \%$ ). For both seasons, there is a net loss, due to mineral processes, of dissolved inorganic carbon as a result of the inferred difference between carbonate production and dissolution. These losses are $-1.30( \pm 0.98) \times 10^{15} \mathrm{mmol} \mathrm{C} \mathrm{yr}^{-1}$ or $-1.27( \pm 0.18) \times 10^{15} \mathrm{mmol} \mathrm{C} \mathrm{yr}^{-1}$ whether or not we consider the boxes in the strait in the summation. This result marks the importance of the biochemical exchanges with the mineral 

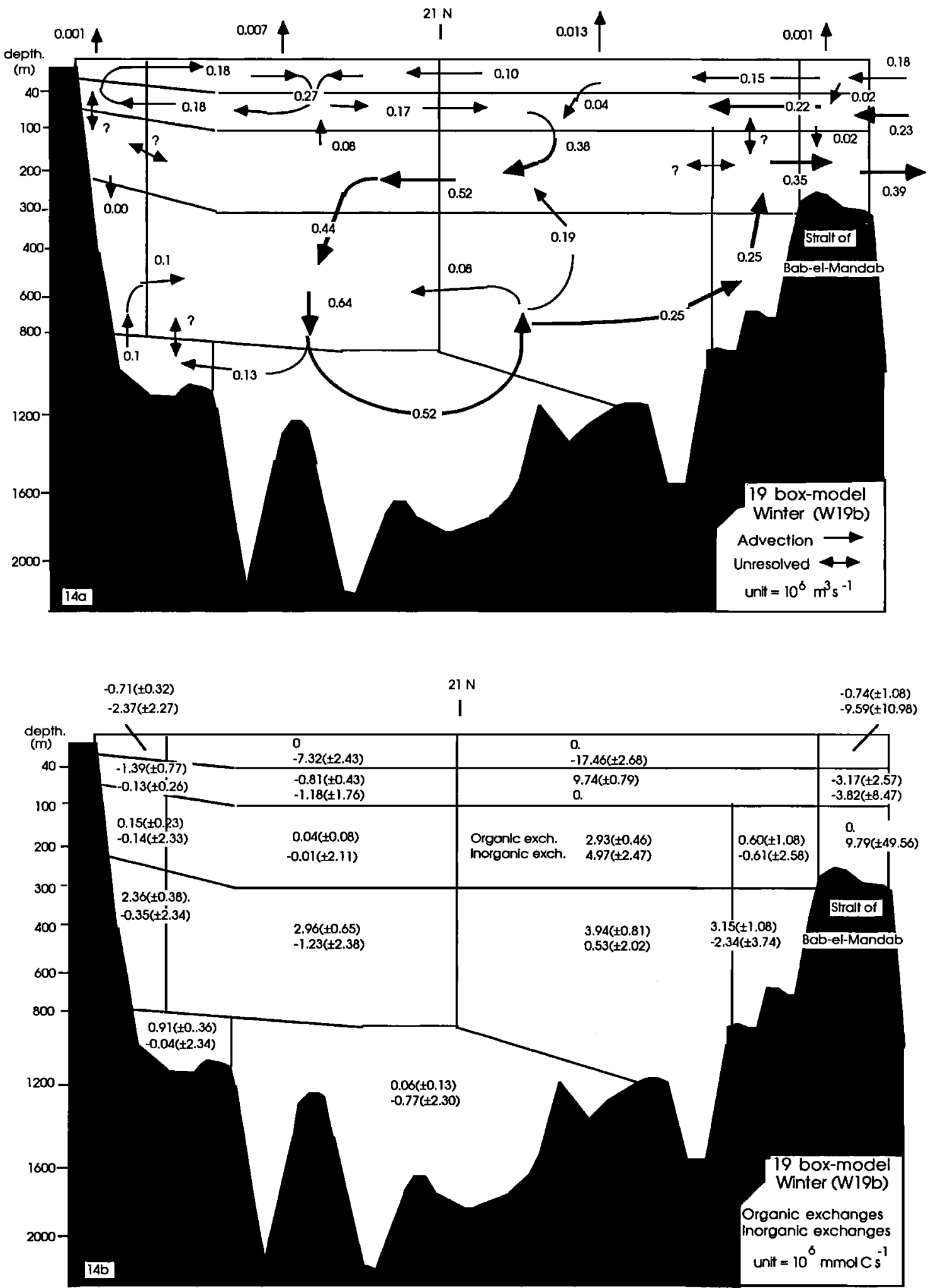

Fig. 14. Same as Figure 12 for W19b. 

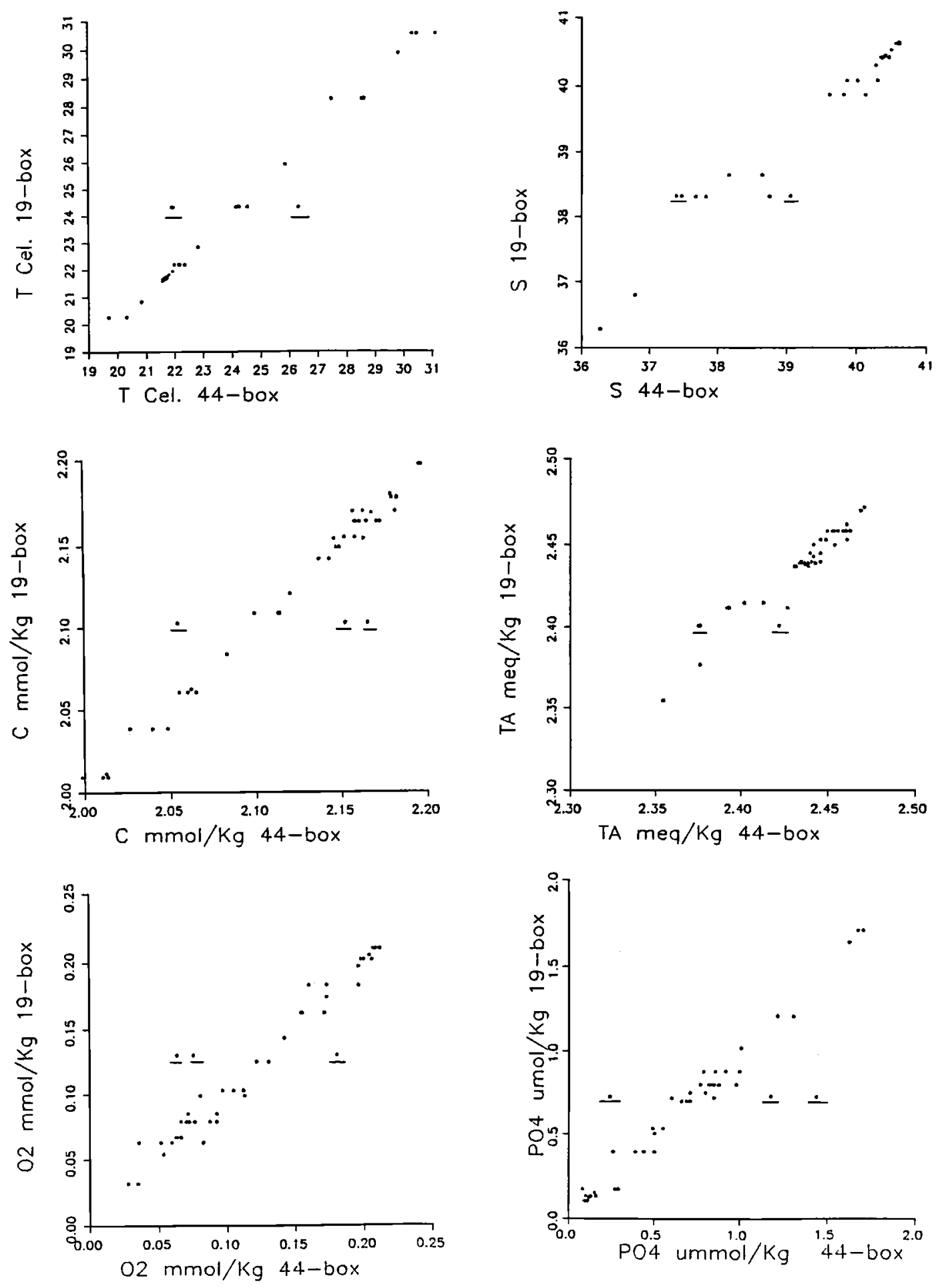

Fig. 15. Nineteen-box data versus 44-box data. From top to bottom and from left to right, potential temperature, salinity, dissolved inorganic carbon, total alkalinity, oxygen and phosphate. In particular, box 12 of 19-box version is underlined. 


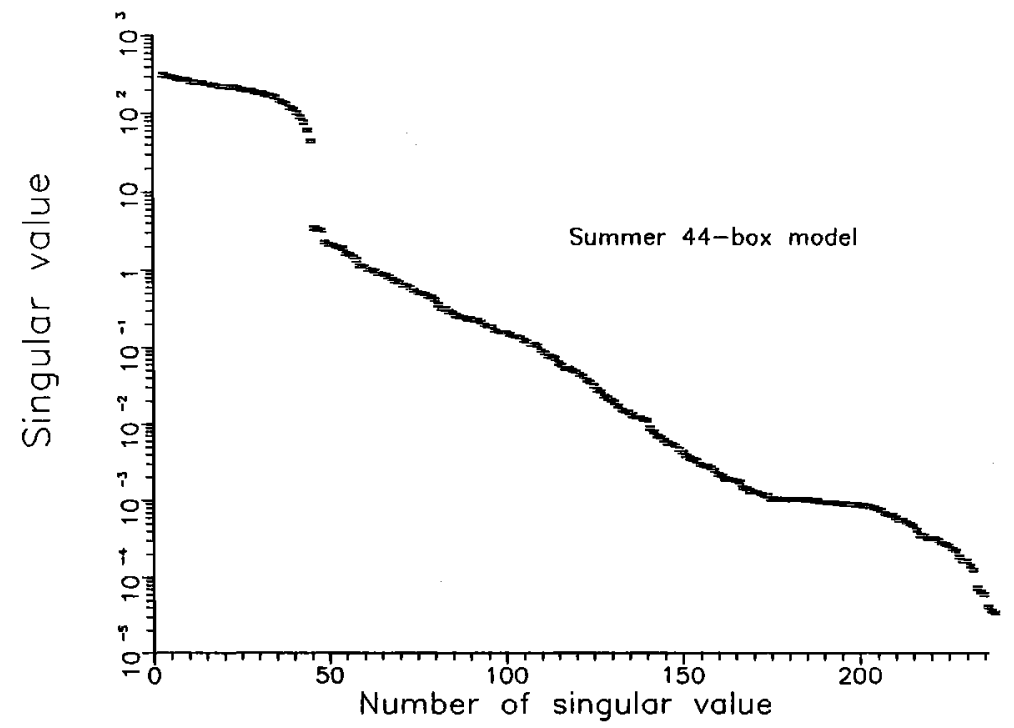

Fig. 16. Singular value decomposition of matrix $\mathbf{A}$ for summer (S44a) application. The first 44 values correspond to the upweighted mass equations.

matter $\left(\mathrm{CaCO}_{3}\right)$ in the Red Sea for the dissolved inorganic carbon budget, which is positive at the Bab-el-Mandab strait (see Souvermezoglou [1985] and Souvermezoglou et al., (1988); see also Figure 7 in that study).

\subsection{The 44-Box Model for Summer}

The number of stations for the summer season ( 10 well-distributed stations) permits us to construct a finer resolution (44 boxes) and more homogeneous partition for volumes which results in a better regard for the tracer information in each box (Figure 15); this new box configuration selection is particularly important in the area where tracer distributions present a large contrast (for example, near the Bab-el-Mandab strait). As in the 19-box application, the matrix $\mathbf{A}$ has more rows than columns (348 equations of tracers budget and 236 unknowns), and we have applied the same convex constraints and perturbations as in the 19-box model (see sections 2.4 and 2.5). The singular value decomposition (Figure 16) of that 44-box version ( $(544 a)$ has the same numerical properties as S19a (Figure 10) and the minimization of $\left\|(\mathbf{A X}-\mathbf{B})_{W}\right\|$ algorithm uses a full rank (236) matrix. Inspection of the residues of properties shows that they are lower on the whole, particularly the residue of mass. It is roughly two thirds of the residue of the S19a version (Table 3), and the same for the residue of the weighted system, $\left\|(\mathbf{A X}-\mathbf{B})_{\mathrm{W}}\right\|$ (we have multiplied the mass equations by a factor of 100). In this sense, one can say the 44-box topology is better suited to explain the observed tracer profiles in the Red Sea : the solutions are more compatible with the left-hand side information (the box data), the right-hand side (the external forcing) and the constraints ( $\mathbf{G X} \geq \mathbf{H}$ ).

The surface flow in S44a (Figure 17a) is toward the south for the major part of basin (nonresolution in north), and is governed by two circulation loops comparable to the summer regime proposed by Patzert [1972]. In this area, the solution differs from S19a; it appears that the major information contrast lies within the phosphate data: the 44-box topology contains a minimum in phosphate which is not present in the 19-box design; instead of $0.12 \mu \mathrm{mol} \mathrm{kg}-1$ (box 7 of $S 19$ a version) the corresponding phosphate values of $S 44 \mathrm{a}$ are $0.15,0.09$ and 0.12 $\mu \mathrm{mol} \mathrm{kg}{ }^{-1}$ (Table 1, boxes 8, 14 and 20 of S44a). That minimum is masked by box data smoothing in the 19-box model, and so the advective solutions are different (interestingly, if we downweight the phosphate budgets, the two versions present the same advection orientation). Another characteristic difference occurs in the southern portion: the vertical advection of water from the Gulf of Aden takes place south of $17^{\circ} \mathrm{N}$, while the $\mathrm{S} 19 \mathrm{a}$ version (Figure 11a), because of the topology, suggested that this response was for the whole southem part of basin. The box data comparison (Figure 15) shows clearly that in this region (box 12) the 19-box formulation did not taken into account all the information, and had composed, by the way, an unrealistic deep circulation for the summer season. Finally, though the advective solutions of S44a differ from S19a, the diffusion still occurs on the 40-m and $100-\mathrm{m}$ interfaces, where the gradients are large.

The solution with the 44-box discretization is more in agreement with the conclusions of several authors, who propose a limit for Aden water influence, at $18^{\circ} 10^{\prime} \mathrm{N}$ in October [Jones and Browning, 1971] or $17^{\circ} \mathrm{N}$ in September [Jones and Browning, 1971, Muromtsev, A. M., A contribution to the hydrology of the Red Sea, Dokl. Akad. Nauk. SSSR, 134, $1443-1446,1960]$. At the $15^{\circ} 30^{\prime} \mathrm{N}$ vertical interface, between 100 and $300 \mathrm{~m}$, our solutions show a mixing of $0.1( \pm 0.02) \mathrm{Sv}$ between the water originating from the Gulf of Aden and deep water coming from the north, forming a dense water slope of $0.26( \pm 0.02)$ Sv. If we sum advections over corresponding 19-box model interfaces, one gets a downward flow of 0.10 $( \pm 0.04) \mathrm{Sv}$ against $0.17( \pm 0.02) \mathrm{Sv}$ in S19a (Figure 11a). In 

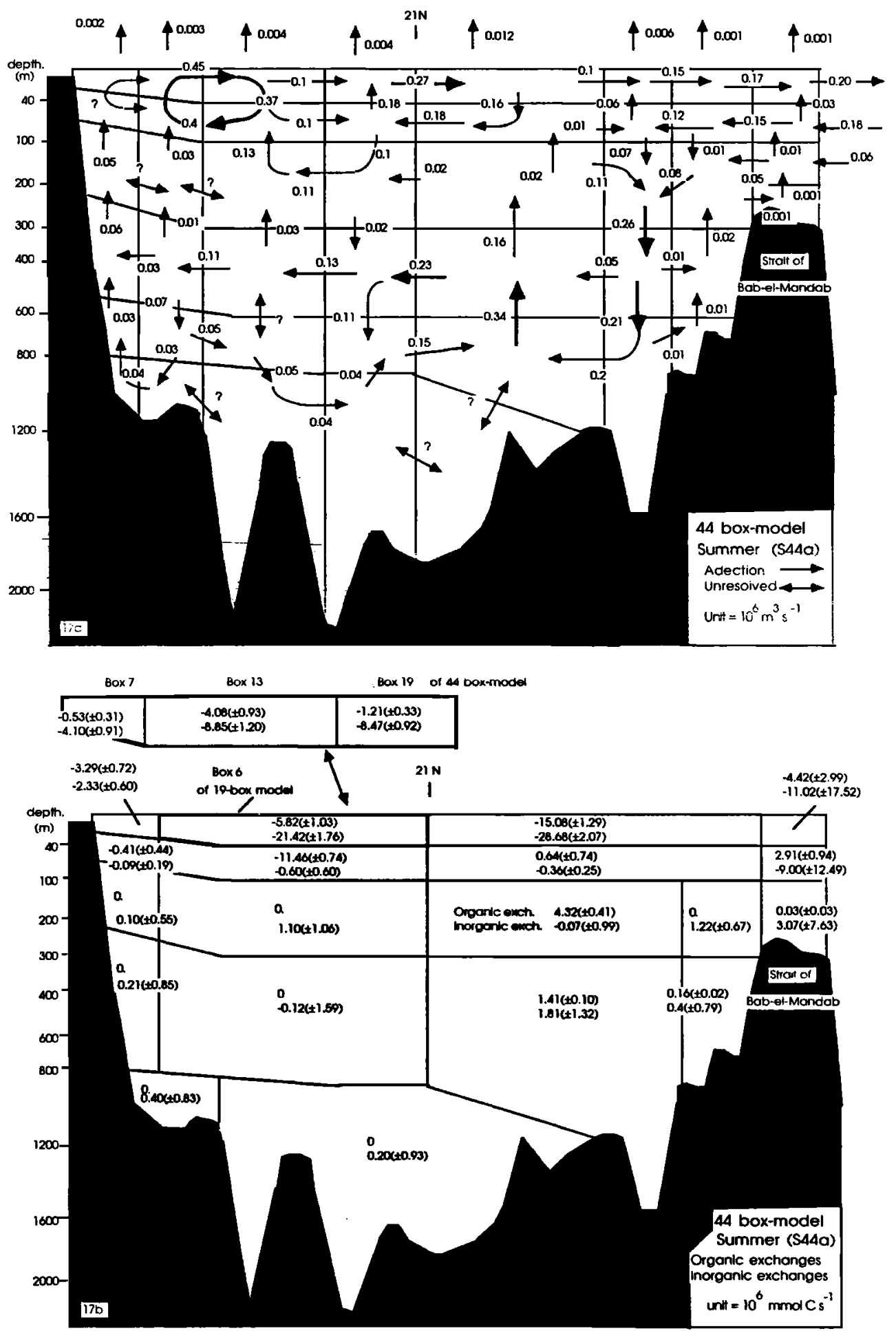

Fig. 17. Fourty-four-box model solutions for summer (S44a). (a) Advection solutions in $10^{6} \mathrm{~m}^{3} \mathrm{~s}^{-1}$ (or sverdrups). The double arrows signal unresolved solutions (standard deviation larger than mean solution). Water forcing terms are also specified at the domain boundaries (atmosphere and Bab-el-Mandab strait). (b) Net exchanges of total inorganic carbon with organic matter (upper number and corresponding deviation) and mineral matter (lower number and corresponding deviation) within each box. Unit in $10^{6} \mathrm{mmol} \mathrm{C} \mathrm{s}^{-1}$. Values are integrated over the corresponding volumes of the 19-box design. 


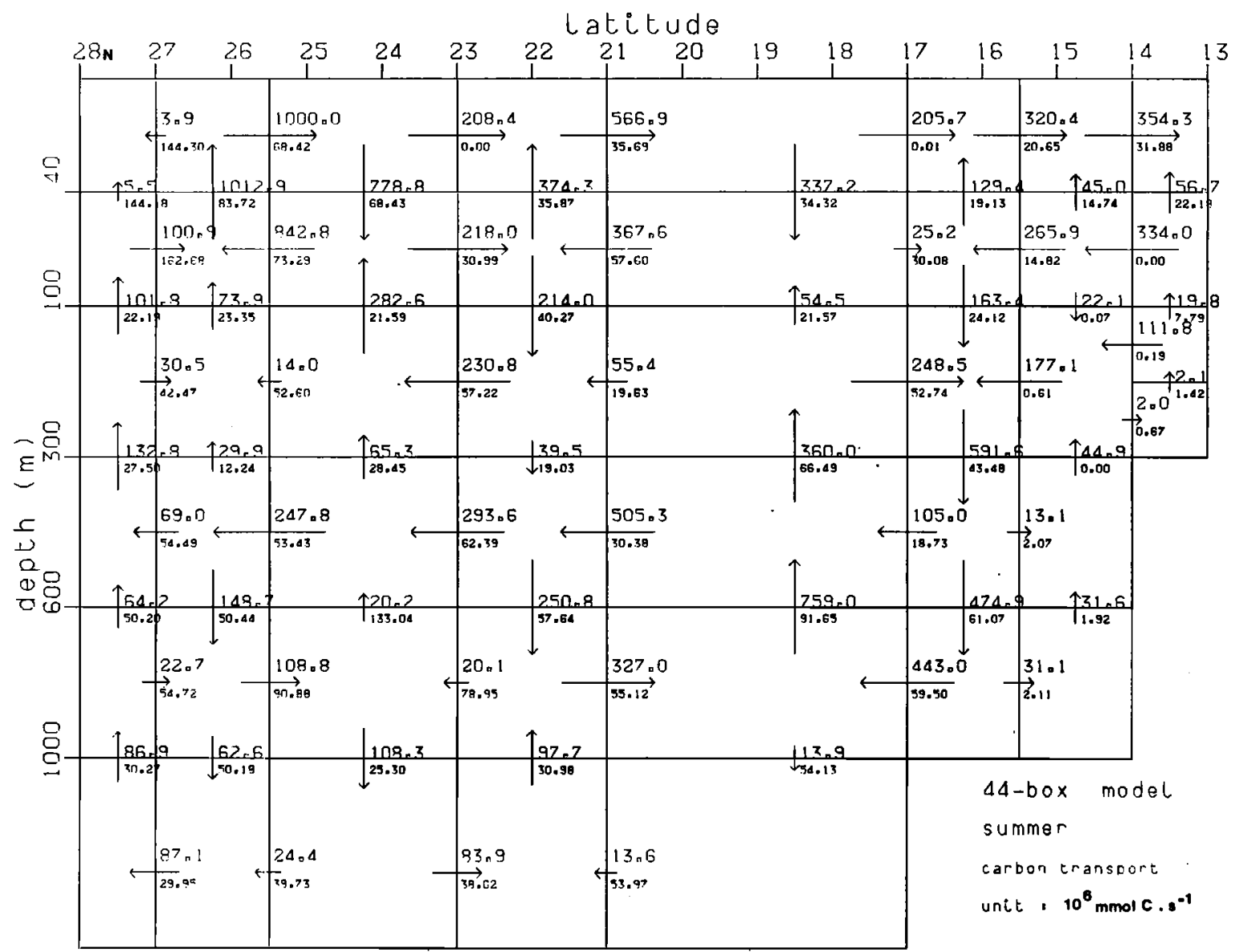

Fig. 18. Total inorganic carbon transport (advection plus diffusion) and corresponding standard deviations, in $10^{6} \mathrm{mmol} \mathrm{C} \mathrm{s}^{-1}$, for $\mathrm{S44a}$. Note that figure is a diagram representation of Red Sea for simplicity in order to show both carbon transport and deviations.

the 19-box model, that downward flow occurs over all the southern portion at the $300-\mathrm{m}$ interface and imposes (by continuity) a northward flow of deep waters. In $\$ 44 a$, the influence of Aden waters is well marked in the south. Consequently, the internal and deep water circulations are not masked in contrast to S19a; S44a presents in the deep basin, an upwelling south of $21^{\circ} \mathrm{N}(0.34( \pm 0.04) \mathrm{Sv})$, maintained in the north $(0.15( \pm 0.02) \mathrm{Sv})$ by Red Sea deep waters, and in the south $(0.20( \pm 0.03)$ Sv) by Red Sea and Aden mixed waters. Wyrtki [1974] has proposed that during the summer season, the deep layers are essentially stagnant. This, however, is not found in our solutions. Nevertheless, since the $\$ 44$ a model gives a deep regime pattern with loop recirculation, one can say that the regime is less dynamically active than the winter one of the 19 -box model. In sum, at $21^{\circ} \mathrm{N}$, the surface $(0.27( \pm 0.02) \mathrm{Sv})$ and deep $(0.15( \pm 0.02) \mathrm{Sv})$ fluxes are directed southward, which counterbalances the central circulation which is oriented northward $(40-600 \mathrm{~m})$.

In Figure $17 \mathrm{~b}$ we present the biochemical exchanges (solutions of the 44-box model) integrated over boxes that correspond to the 19-box model. Interestingly, though the advective exchanges are different when we change the discretization, the solutions for carbon exchanges by the biology for S44a are rather similar to the S19a solutions (Figure 11b). There is, in fact, a box equivalence for the $\mathrm{CO}_{1}$ and $\mathrm{cm}_{\mathrm{i}}$ unknowns; for instance, the boxes 7,13 and 19 of S44a (on top of Figure 17b) have a total carbon loss by organic and mineral net productions respectively of $-5.82( \pm 1.03) \times 10^{6}$ mmol C s$~^{-1}$ and $-21.42( \pm 1.76) \times 10^{6} \mathrm{mmol} \mathrm{C} \mathrm{s}^{-1}$, against -4.04 $( \pm 1.11) \times 10^{6} \mathrm{mmol} \mathrm{C} \mathrm{s}^{-1}$ and $-18.55( \pm 2.37) \times 10^{6} \mathrm{mmol} \mathrm{C} \mathrm{s}^{-1}$ for the corresponding box 6 in S19a (Figure 11b). As in S19a, the solution of S44a shows a net organic production in the north, between 40 and $100 \mathrm{~m}$ (an area of upward motion). The dissolution occurs in the south, where there is a downward flow of mixed Red Sea and Aden waters. For the whole basin, the production is greater than dissolution, as in the 19-box version. The losses of dissolved carbon are $-0.31( \pm 0.04) \times 10^{8} \mathrm{mmol} \mathrm{C}$ $\mathrm{s}^{-1}$ for the organic exchanges and $-0.65( \pm 0.19) \times 10^{8} \mathrm{mmol} \mathrm{C}$ $\mathrm{s}^{-1}$ for the mineral processes, which corresponds to a total seasonal net loss of $-1.36( \pm 0.26) \times 10^{15} \mathrm{mmol} \mathrm{C}$ summer-1, which is close to the value of $-1.18( \pm 0.19) \times 10^{15} \mathrm{mmol} \mathrm{C}$ summer-1 given with the 19 box-model (S19a). 


\section{CONCLUSIONS}

The seasonal uncoupling in the box model approach is a realistic formulation for the Red Sea. With the use of seasonal information (tracer data), the inverse methodology extracts the within seasonal compatibility of both dynamical and biochemical processes. When the two seasons are uncoupled, the model produces solutions that reflect the well-known reversal circulation in Red Sea surface layers. Each solution presents a seasonal circulation scheme for the deep regime, principally characterized by the internal recirculation (strongest during winter). The solutions with respect to biochemical processes also show a seasonal evolution; there is a loss of carbon by exchanges with mineral matter during both seasons, while the organic system is close to a yearly balance

(dissolution during winter, production during summer). The negative yearly budget of mineral processes in the basin could be explained by the importation of carbon from the Gulf of Aden.

The 44-box version provides a more realistic picture which is consistent with the fact that it contains more information on tracer distribution. If one does not use all information of tracers that one could, certain dynamical solutions could be reversed. That explains the different advective surface solutions (between S19a and S44a) in the northern portion of the Red Sea as well as the opposite pattern of deep circulation. For those who are interested in sampling tracer data in the Red Sea, the 44-box design represents the largest spatial scale that one needs along the basin in order to select main geochemical feature within the basin.

Changing the convex constraints (W19a and W19b), we have obtained several different solutions. However, the correspondence of biochemical activities, for the two discretization versions ( $\mathrm{S} 19 \mathrm{a}$ and $\mathrm{S44a}$ ), shows that processes (dynamical and biochemical) provide independent information. It is interesting to note that in a global ocean application, Minster and Garçon [1987] found that total particulate carbon flux is robust when one changes the design of the model. In our Red Sea application, results of biochemical exchanges are very similar from one design (19-box) to the other (44-box), even if the transport is different. But, the model favors the resolutions of large exchanges (transport) and resolves only the nonnegligible biochemical processes in the property budgets. We obtain a reasonable new production estimate for surface and subsurface waters which takes place in the expected area (upwelling). Though some solutions also reflect dissolution of organic matter, half of biochemical processes are unresolved (they are in the noise of transport terms).

To ameliorate the resolution of these processes, and consequently the compatibility between the dynamical and biochemical solutions, one needs to have better information on the sedimentation and production exchanges. More generally, and as was noted by Bolin et al. [1987], it is particularly important to have a better knowledge of the external exchanges. One aim, in the utilization of tracer distribution, is to quantify the fluxes of carbon in the oceans, then between the oceans and the atmosphere, with a better accuracy than the anthropogenic perturbation itself. However, the carbon advective-diffusive transport (Figure 18) is at least one order of magnitude greater than ocean-atmosphere and biochemical exchanges (Figure 17b). The standard deviations of carbon transport (in the sense of the model perturbations) are often larger than external and internal fluxes.

We have seen that refining the topology (19 to 44 boxes) permits a better resolution, but we can not quantitatively conclude the carbon budget for a specific box. To remove this handicap and attempt to apply the solutions on a temporal integration scheme (for example, carbon cycle perturbations), it would be necessary to have better external and dynamical constraints.

Acknowledgments. This work was supported by NASA. contract NAGW848, National Science Foundation contract 19X-55922C, and Centre National de la Recherche Scientifique contract ATP/FMO 981075. The Merou cruises on board the R/V Marion Dufresne was supported by les Terres Australes et Antarctiques Françaises (TAAF).

\section{REFERENCES}

Andrié, C., C. Oudot, C. Genthon, and L. Merlivat, $\mathrm{CO}_{2}$ fluxes in the tropical Atlantic during FOCAL cruises, J. Geophys. Res., 91, (C10), 11,741-11,755, 1986.

Beauverger, C., C. Brunet, and A. Poisson, Les rapports des campagnes à la mer, MD33/Merou, Les Publ. Mission Rech., 82,04, Terres Australes et Antarctiques Fr., Paris, $1984 a$.

Beauverger, C., C. Brunet, and A. Poisson, Les rapports des campagnes à la mer, MD33/Merou, Les Publ. Mission Rech., 82,05, Terres Australes et Antarctiques Fr., Paris, $1984 b$.

Beckmann, W., Mesozooplankton distribution on a transect from the Gulf of Aden to the central Red Sea during the winter monsoon, Oceanol. Acta, 7, (1), 87-102, 1984.

Bolin, B., A. Bjorkstrom, K. Holmen, and B. Moore, The simultaneous use of tracers for ocean circulation studies, Tellus, 35B, 206-236, 1983.

Bolin, B., A. Bjorkstrom, K. Holmen, and B. Moore, On inverse methods for combining chemical and physical oceanographic data: A steady-state analysis of the Atlantic Ocean, On the Utilization of Chemical Tracer Data for Oceanic Biogeochemical Models, With Special Regard to Carbon Transfers, doctoral thesis, Dep. of Chem. Meteorol., Univ. of Stockolm, 1987.

Brun-Cottan, J. C., Vertical transport of particles within the ocean, in The Role of Air-Sea Exchange in Geochemical Cycling, edited by P. Buat-Ménard, pp. 83-111, D. Reidel, Hingham, Mass., 1986.

Garçon, V., and J. F. Minster, Heat, carbon and water fluxes in a 12 box model of the world ocean, Tellus, 40B, 161-177, 1988.

Grasshoff, K., Zur Chemie des Roten Meeres und des inneren Golfs von Aden nach Beobachtungen von F.S. "Meteor" wahrend der indischen Ozean Expedition 1964/1965, "Meteor" orschungsergeb., Reihe A, 6, 1-76, 1969.

Hastenrath, S., and P. J. Lamb, Climatic Atlas of the Indian Ocean, University of Wisconsin Press, Madison, 1979.

Jones, E. N., and D. G. Browning, Cold water layer in the southern Red Sea, Limnol. Oceanogr., 16, 503-509, 1971.

Khimitsa, V. A., and, V. A. Bibik, Seasonal exchange in 
dissolved oxygen and phosphates between the Red Sea and the Gulf of Aden, Oceanology, 19, (5), 514-516, 1979.

Kuntz, R., Bestimmung der Tiefenwasserzirkulation des Roten Meeres anhand einer Boxmodellauswertung von Tritium-, $3 \mathrm{He}$ - und Salinitatsdaten. Ph. D. thesis, 76pp., Ruprecht Karls Univ., Heidelberg, Federal Republic of Germany, 1985. Lawson, C. L. and, R. J. Hanson, Solving Least Squares Problems, 340 pp., Prentice-Hall, Englewood Cliffs, N. J., $340,1974$.

Liss, P. S., and L. Merlivat, Air-sea gas exchange rates: Introduction and synthesis, in The Role of Air-Sea Exchange in Geochemical Cycling, edited by P. Buat-Ménard, pp. 113-127, D. Reidel, Hingham, Mass., 1986.

Maillard, C.,. Etude hydrologique et dynamique de la Mer Rouge en hiver, Ann. Inst. Océanogr., Paris, XLVIII, (2), 113-140, 1972.

Maillard, C., Eaux intermédiares et formation d'eau profonde en Mer Rouge, in L'Océanographie Physique de la Mer Rouge, IAPSO-UNESCO-SCOR Symposium, Actes de Colloques, vol. 2, pp. 105-130, Centre National pour l'Exploitation des Océans, Paris, 1974.

Maillard, C. and, G. F. Soliman, Les rapports des campagnes à la mer, MD33/Merou, Les Publ. Mission Rech., 82,06, Terres Australes et Antarctiques Fr., Paris, 1985.

Manins, P. C., A filling box model of the deep circulation of the Red Sea. Mém. Soc. R. Sci. Liège, Ser. 6, VI, 153-166, 1973.

Menke, W., Geophysical Data Analysis: Discrete Inverse Theory, 260 pp., Academic, San Diego, Calif., 1984.

Mercier, H., Determinig the general circulation of the ocean: A nonlinear inverse problem, J. Geophys. Res., 91, (C4), 5103-5109, 1986.

Minster, J. F., and V. Garçon, New production and the ocean carbon fluxes, Adv. Space Res., 7, (2), 121-126,1987.

Morcos, S. A., Physical and chemical oceanography of the Red Sea, Oceanogr. Mar. Biol., 8, 73-202, 1970.

Morcos, S. A., and G. F. Soliman, Circulation and deep water formation in the northern Red Sea in winter (based on R/V Mabahiss sections, January-February, 1935), in L'Océanographie Physique de la Mer Rouge, IAPSO-UNESCO-SCOR Symposium, Actes de Colloques, vol. 2, pp. 91-103, Centre National pour l'Exploitation des Océans, Paris, 1974.

Naqvi, S. W. A., H. P. Hansen, and T. W. Kureishy, Nutrient uptake and regeneration ratios in the Red Sea with reference to the nutrient budgets, Oceanol. Acta, 9, (3), 271-275, 1986.

Neumann, A. C. and, D. A. McGill, Circulation of the Red Sea in early summer, Deep Sea Res., 8, 223-235, 1962.

Papaud, A., and A. Poisson, Distribution of dissolved $\mathrm{CO}_{2}$ in the Red Sea and correlations with other geochemical tracers, J. Mar. Res., 44, 385-402, 1986.

Patzert, W. C., Seasonal variations in structure and circulation in the Red Sea. Ph. D. thesis, Dep. of Oceanogr., Univ. of Hawaii, Honolulu, 1972.
Patzert, W. C., Wind-induced reversal in Red Sea circulation, Deep Sea Res., 21, 109-121, 1974.

Phillips, O. M., On turbulent convection currents and the circulation of the Red Sea, Deep Sea Res., 13, 1149-1160, 1966.

Poisson, A., S. Morcos, E. Souvermezoglou, A. Papaud, and A. Ivanoff, Some aspects of biogeochemical cycles in the Red Sea with special reference to new observations made in summer 1982, Deep Sea Res., 31, 707-718, 1984.

Redfield, A. C., B. H. Ketchum, and F. A. Richards, The influence of organisms on the composition of sea water, in The Sea, vol. 2, edited by M. N. Hill, pp. 26-77, Interscience, New York, 1963.

Schlitzer, R., Renewal rates of east Atlantic deep water estimated by inversion of ${ }^{14} \mathrm{C}$ data, J. Geophys. Res., 92 , 2953-2961, 1987.

Souvermezoglou, E., Le cycle biogéochimique du gaz carbonique en Mer Rouge: Première approche, thèse de 3eme cycle, Univ. Pierre et Marie Curie, Paris, 1985.

Thiel, H., and H. Weikert, Biological oceanography of the Red Sea oceanic system, Deep Sea Res., 31, 829-831, 1984.

Thompson, E. F., Chemical and physical investigations: The general hydrography of the Red Sea. John Murray Expedition 1933-34, Sc. Rep. 2(3), 83-103, 1939.

Weiss, R. F., W. S. Broecker, H. Craig, and D. Spencer, GEOSECS Indian Ocean Expedition, vol. 5, Hydrological Data, U.S. Government Printing Office, Washington, D. C., 1983.

Wunsch, C., An eclectic Atlantic Ocean circulation model, I, The meridional flux of heat, J. Phys. Oceanogr., 14, 1712-1733, 1984.

Wunsch, C., and J. F. Minster, Methods for box models and ocean circulation tracers: Mathematical programming and nonlinear inverse theory, J. Geophys. Res., 87, 5647-5662, 1982.

Wyrtki, K., The oxygen minima in relation to ocean circulation, Deep Sea Res., 9, 11-23, 1962.

Wyrtki, K., On the deep circulation of the Red Sea, in L'Océanographie Physique de la Mer Rouge. IAPSO-UNESCO-SCOR Symposium, Actes de Colloques, vol. 2, pp. 135-159, Centre National pour l'Exploitation des Océans, Paris, 1974.

N. Metzl, A. Papaud, and Alain Poisson, Laboratoire de Physique et Chimie Marines, Université P. et M. Curie, Tour 24-25, 4, Place Jussieu, 75230 Paris Cedex 05, France.

B. Moore III, Institute for the Study of Earth, Oceans, and Space, Science and Engineering Research Building, University of New Hampshire, Durham, NH 03824, U.S.A.

(Received April 21, 1988; revised November 14, 1988; accepted November 15, 1988.) 